University of Puget Sound

Sound Ideas

All Faculty Scholarship

Faculty Scholarship

$1-1-1985$

\title{
Pictet's experiment: The apparent radiation and reflection of cold
}

James C. Evans

University of Puget Sound, jcevans@pugetsound.edu

Brian Popp

Department of Physics FM-15, University of Washington, Seattle, Washington 98195

Follow this and additional works at: http://soundideas.pugetsound.edu/faculty_pubs

\section{Citation}

Evans, James C., and B. Popp. 1985. "Pictet Experiment - the Apparent Radiation and Reflection of Cold." American Journal Of Physics 53(8): 737-753.

This Article is brought to you for free and open access by the Faculty Scholarship at Sound Ideas. It has been accepted for inclusion in All Faculty Scholarship by an authorized administrator of Sound Ideas. For more information, please contact soundideas@pugetsound.edu. 


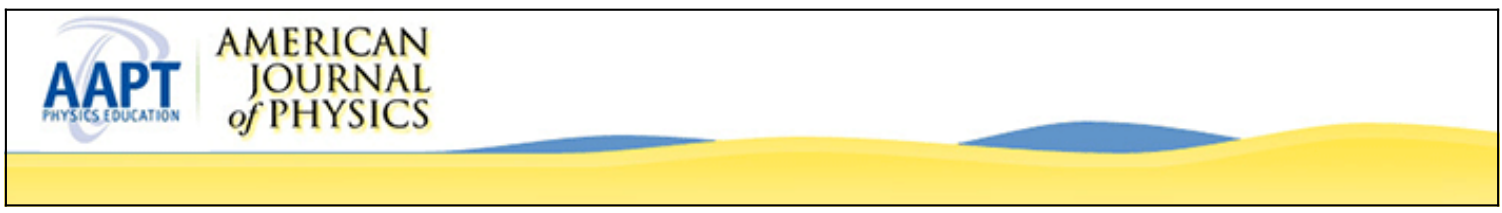

Pictet's experiment: The apparent radiation and reflection of cold

James Evans and Brian Popp

Citation: American Journal of Physics 53, 737 (1985); doi: 10.1119/1.14305

View online: http://dx.doi.org/10.1119/1.14305

View Table of Contents: http://scitation.aip.org/content/aapt/journal/ajp/53/8?ver=pdfcov

Published by the American Association of Physics Teachers

\section{Articles you may be interested in}

Radiation absorption and reflection by a plasma with cold and hot electrons

Phys. Plasmas 10, 3344 (2003); 10.1063/1.1590981

Experiments in cold and ultracold collisions

AIP Conf. Proc. 205, 607 (1990); 10.1063/1.39233

Response to Penn's "Comment on Pictet's experiment"

Am. J. Phys. 54, 106 (1986); 10.1119/1.14864

Comment on Pictet's experiment

Am. J. Phys. 54, 106 (1986); 10.1119/1.14697

The Apparent Reduction of Loudness: A Repeat Experiment

J. Acoust. Soc. Am. 27, 326 (1955); 10.1121/1.1907523

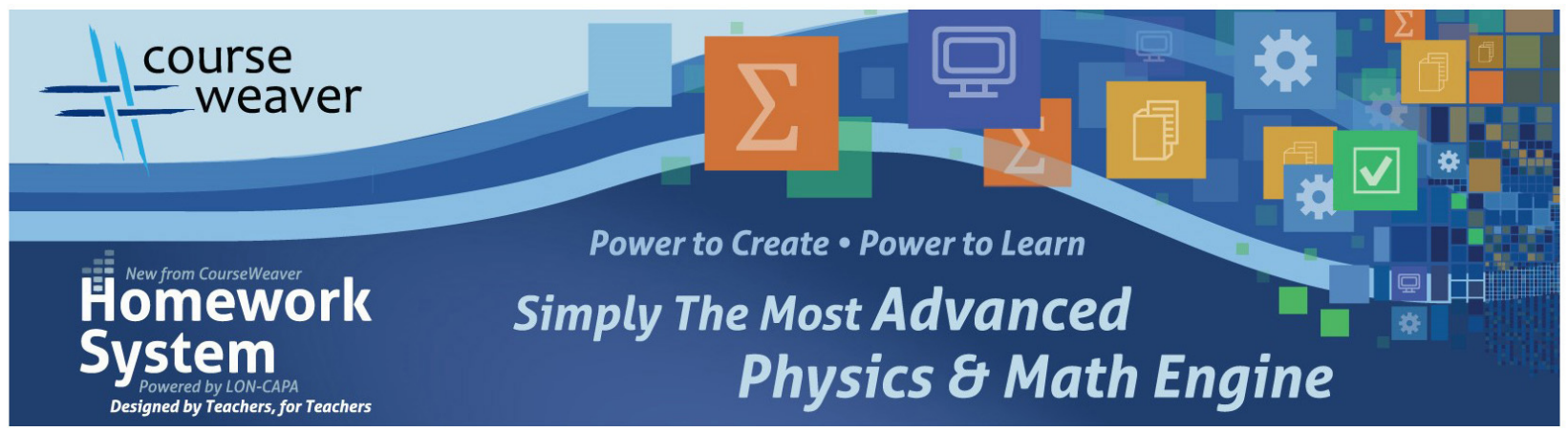


(a)

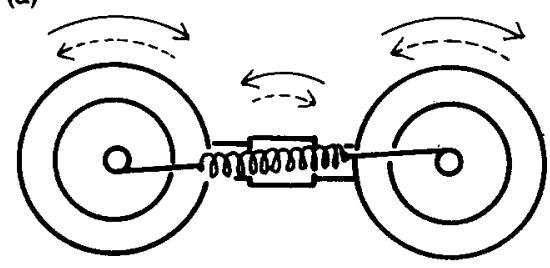

(b)

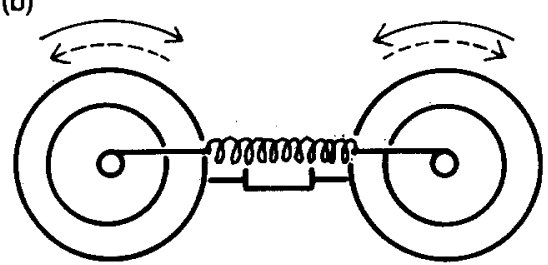

Fig. 3. (a) Demonstration of nondissipative spin-orbit coupling. The sense of rotation of both wheels is identical and opposite to that of the system as a whole. Both senses of rotation oscillate in sign. (b) Demonstration of nondissipative spin-spin coupling. The wheels rotate back and forth in opposite directions. The system as a whole remains at rest.

fer of angular momentum. After releasing the system, both $\mathbf{L}_{A}$ and $\mathbf{L}_{B}$ increase. In order to keep the total angular momentum $\mathbf{L}_{A}+\mathbf{L}_{B}+\mathbf{L}_{A B}$ constant, $\mathbf{L}_{A B}$ has to increase by the negative of $\mathbf{L}_{A}+\mathbf{L}_{B}$. A similar phenomenon occurs within an atom with spin-orbit coupling. Of course, in the atom, the angular momentum does not change by changing the amount of the spin angular momentum of the electron (which is not possible) but rather by changing its direction.

If both wheels are initially turned by the same number of turns in opposite directions and then released, the increase of $\mathbf{L}_{A}$ is the negative of the increase of $\mathbf{L}_{B}$ [Fig. 3(b)]. Then the sum $\mathbf{L}_{A}+\mathbf{L}_{B}$ always remains zero. Both wheels turn "back and forth" but $A$ always in the opposite sense of direction of $B$ and the bar $S$ remains at rest. Angular momentum is exchanged only between $A$ and $B$, but not with $A B$. This is a model of spin-spin coupling.

Although in all these demonstrations quantitative measurements can be made, the main message of the experiments is to display angular momentum transfer in a very direct and convincing way.

'W. C. Conolly and R. C. Conolly, Am. J. Phys. 41, 131 (1973).

${ }^{2}$ R. R. Rockefeller, Am. J. Phys. 43, 981 (1975).

${ }^{3}$ H. Klosterguard, Am. J. Phys. 44, 21 (1976).

${ }^{4}$ R. B. Prigo and M. Reading, Am. J. Phys. 45, 636 (1977).

${ }^{5}$ S. Datta, Am. J. Phys. 46, 1190 (1978).

${ }^{6}$ R. P. Feynman, R. B. Leighton, and M. Sands, The Feynman Lectures on Physics (Addison-Wesley, Reading, MA, 1964), Sec. 20-3.

${ }^{7}$ R. Resnick and D. Halliday, Physics for Students of Science and Engineering (Wiley, New York, 1963), Sec. 13-4.

${ }^{8}$ C. Kittel, W. D. Knight, and M. A. Ruderman, Mechanics, Berkeley Physics Course Volume 1 (McGraw-Hill, New York, 1973), Chap. 6.

${ }^{9} \mathrm{G}$. Falk and W. Ruppel, Mechanik, Relativität, Gravitation (SpringerVerlag, New York, 1975), p. 250.

${ }^{10} \mathrm{G}$. Falk and W. Ruppel, Energie und Entropie (Springer-Verlag, New York, 1976), pp. 162-163.

\title{
Pictet's experiment: The apparent radiation and reflection of cold
}

\author{
James Evans \\ Department of Physics, University of Puget Sound, Tacoma, Washington 98416 \\ Brian Popp \\ Department of Physics FM-15, University of Washington, Seattle, Washington 98195
}

(Received 9 February 1984; accepted for publication 4 April 1984)

Towards the end of the eighteenth century it was discovered by Marc-Auguste Pictet of Geneva that cold emanations from a flask of snow could be reflected and focused by mirrors in the same way as the emanations from a heated object. Pictet's discovery had an invigorating effect on research on radiant heat. We sketch the scientific milieu in which Pictet worked, describe the line of investigation that led him to his discovery, and summarize the theoretical explanations offered by Pictet and his contemporaries for this and related experiments. A simple qualitative explanation in modern terms is offered for the apparent radiation and reflection of cold. Finally, detailed directions are provided for replicating the experiment as a demonstration for the lecture hall.

\section{INTRODUCTION}

In the summer and fall of the year 1800, Count Rumford passed several months in Edinburgh. During his stay he continued the research on heat that had occupied his atten- tion, on and off, for a number of years. One day, in the company of Professors Hope, Playfair, and Stewart ${ }^{1}$ of the University of Edinburgh, he undertook to repeat an experiment that had been performed originally by Marc-Auguste Pictet of the Academy of Geneva- a dramatic demonstra- 


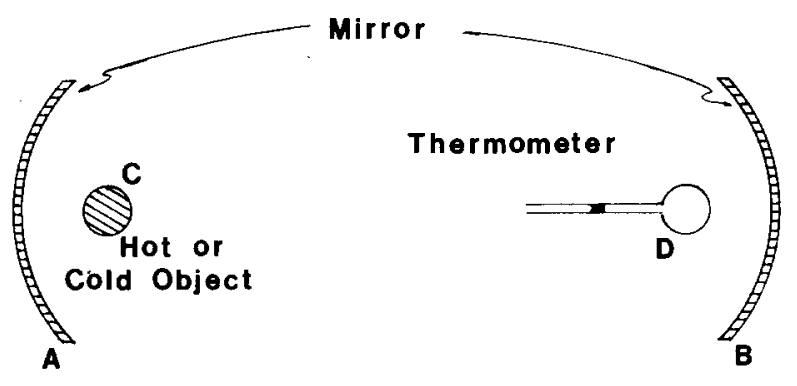

Fig. 1. Illustrating Pictet's experiments with hot and cold emanations.

tion of the radiation and reflection of cold.

Two metallic mirrors $A$ and $B$, each $15 \mathrm{in}$. in diameter, with focal lengths of 15 in., were placed opposite one another at a distance of $16 \mathrm{ft}$ (see Fig. 1). A sensitive air thermometer was placed at the focus $D$ of one mirror. When a cold object (in this case, a glass bulb filled with water and pounded ice) was placed at the other focus $C$, the thermometer at $D$ began immediately to descend. If, instead of being placed directly in the focus, the thermometer was displaced a short distance to the side, the cold body ceased to exert its former cooling power. Evidently, cooling emanations from the bulb of ice water were being reflected and focused by the mirrors.

The inverse experiment, of collecting and focusing heat by means of concave mirrors, is today a popular lecture demonstration. Pictet's experiment, involving the apparent radiation and reflection of cold, is not very widely known. Most physicists, on seeing it demonstrated for the first time, find it surprising and even puzzling. Apparently the situation was the same in Rumford's day. Indeed, the experiment must have provoked a lively discussion, for Rumford remarks that it was on this occasion that he first publicly announced his opinion on the subject of heat. It was not possible, said Rumford, that caloric had an actual existence. Rather, heat was a vibration, like sound, and was transmitted in an analogous manner. "The cold body in one focus compels the warm body (the thermometer) in the other focus to change its note."2

Pictet's discovery of cold emanations had an invigorating effect on research in radiant heat. It was, as we shall see, the direct stimulus both for Rumford's experimental studies and for Pierre Prevost's influential theory of dynamic equilibrium. The present article is devoted to this swirl of activity around the problem of the radiation and reflection of cold. Attention centers on a small group of physicists, most of whom knew one another, and most of whom were connected in some way with the Academy of Geneva. The relations of these physicists among themselves and their influences on one another are particular objects of study.

The article is divided into four sections. In the first, we treat Pictet's experimental discovery of cold emanations. To indicate Pictet's place in eighteenth-century physics, we sketch the understanding of radiant heat that had been achieved by his predecessors and discuss his influence on contemporary experimentalists, and notably on Rumford. In Sec. III we examine the physical explanations of the strange phenomenon given by Pictet and others. In Sec. IV we offer a simple, qualitative explanation in modern terms. Finally, in Sec. V we provide directions for replicating Pictet's experiment in the laboratory or lecture hall with inexpensive apparatus.

\section{PICTET'S AND RELATED EXPERIMENTS WITH RADIANT HEAT, 1770-1804}

\section{A. Context of Pictet's experiment}

References to experiments with radiant heat appear in Italian, English, French, and German publications scattered over a period of 200 years, from 1570, say, to 1770 . Knowledge of the single most basic phenomenon-the reflection and concentration of heat by curved mirrors-is, of course, a legacy of Greek antiquity: witness the story of the burning mirrors of Archimedes. Down to 1770, however, the experimentation was desultory and undirected. One finds the same handful of familiar demonstrations repeated, often independently, by experimenters separated from one another in time and place. ${ }^{3}$

In one very popular and dramatic demonstration, a combustible object situated between two concave mirrors was ignited at a distance of 20 or $24 \mathrm{ft}$ by the reflection and concentration of the heat of a single coal, the coal being placed at the focus of one mirror and the combustible object at the focus of the other. ${ }^{4}$

The nature of the emanations that produced this spectacular effect was the subject of a debate that was long to continue. Serious experimental work on radiant heat got under way in the decade of the 1770's, and already by 1780 two important results had been obtained. First, radiant heat had been distinguished from "ordinary heat," i.e., from convection and conduction effects. And, second, radiant heat had been clearly separated from light, although it was known to obey the same optical laws as light. In these developments, the two writers most noteworthy, both for the clarity of their demonstrations and for their influence on the Swiss school, were J..H. Lambert ${ }^{5}$ and C. W. Scheele. ${ }^{6}$

The separation of light and heat proved to be relatively easy. Heat, of course, habitually exists without light in countless situations of everyday life-light ordinarily being produced only when the heat is excessive. The more delicate question was therefore whether light could exist without heat. A demonstration was readily at hand. Lambert, among many others, pointed out that a pane of transparent glass protects the face from the heat of even the fiercest fire until the glass itself grows hot. And again, Lambert used a large lens to collect the light from a very hot fire lit in the hearth of a chimney and found that the heat produced at the focus was scarcely sensible to the hand. Lambert therefore distinguished between the light or luminous heat that passed through the glass unaffected and the obscure heat (or heat without light) whose progress was halted by glass. ${ }^{7}$

Through a series of thoughtfully organized experiments, Scheele gave one of the clearest demonstrations of the differences between convective and radiant heat. Of his many arguments, we shall cite but three.

(1) Let the experimenter place himself before a stove with an open door, and with such a fire that at a distance of $10 \mathrm{ft}$ he can still plainly feel its heat. There is a constant current of air from the room into the stove to replace the air that the heat has dilated and that has consequently gone up the chimney. How is it that heat continues to pour forth into the room rather than being entrained by the air and taken up the chimney?

(2) Agitate the air from left to right very briskly before the open door of the stove. Let the experimenter approach the stove from the right side with his face. He will feel the 
wind that crosses the path of the heat emanations, but it will not feel warm.

(3) When a metal mirror, whether concave or plane, is used to reflect heat emanations, the mirror does not become warm. But if the same metal mirror is placed in contact with a hot body, it very quickly becomes warm. For an example of this, close the flue of the stove, so that warm air immediately leaves the mouth of the stove and rises through the room. Hold the metal mirror in this vertically ascending heat. The metal is quickly warmed. Nor can this heat be reflected.

Scheele concluded that the heat which rises in the stove with the air and which escapes through the chimney is quite different from that which shoots out of the door into the farthest reaches of the room. The latter travels in straight lines; it is reflected by metal mirrors at an angle equal to the angle of incidence; it does not combine with air; and its original direction is not changed by currents of air. To distinguish this kind of heat from the kind that combines with air and is affected by wind, Sheele used the term "radiant heat" (strahlende Hitze). ${ }^{8}$

When we say that radiant heat had been distinguished from light, as well as from convection and conduction effects, we mean only that these phenomena had all been investigated and that more or less marked differences had been recognized among them. In theoretical discussions, the separation was often much less clear. For example, even Scheele, whose admirable experiments had contributed the most to these new distinctions, believed that light, radiant heat, and ordinary heat were identical in essence and differed only in degree. They differed particularly in their elasticity, as revealed by the distances they could travel before combining with the air. Light was the most elastic of the three and could penetrate great quantities of air. Radiant heat also had a remarkable elasticity but could not travel nearly so far before combining with the air. Finally, ordinary heat was quite inelastic and was therefore always found in combination with other substances. For Scheele, a molecule of heat was composed of an atom of oxygen (which he called "fire-air") combined with a little phlogiston. Now, fire-air was capable of combining with a variable amount of phlogiston. Moreover, the addition of phlogiston gave the compound a greater elasticity. When fire-air is attached to a little more phlogiston than is necessary to produce heat, there results radiant heat. If the proportion of phlogiston is increased a little more, the properties observed in radiant heat are augmented, and light is formed. Moreover, different colors of light depend upon only an atom of phlogiston more or less. ${ }^{9}$

Although Scheele's experiments were admired in Geneva, his theory did not find much favor there, where rather different views prevailed. The example of Scheele, however, should remind us that experimental results which appear to a modern reader to have very clear interpretations did not necessarily call forth such interpretations in their own day. It is against a background of a handful of secure experimental results and a welter of conflicting interpretations that one must view the investigations of radiant heat conducted in Geneva by Saussure and Pictet, to which we now turn.

\section{B. Investigations of Saussure and Pictet}

Horace-Bénédict de Saussure (1740-1799), not very well known in the United States, is something of a Swiss nation-

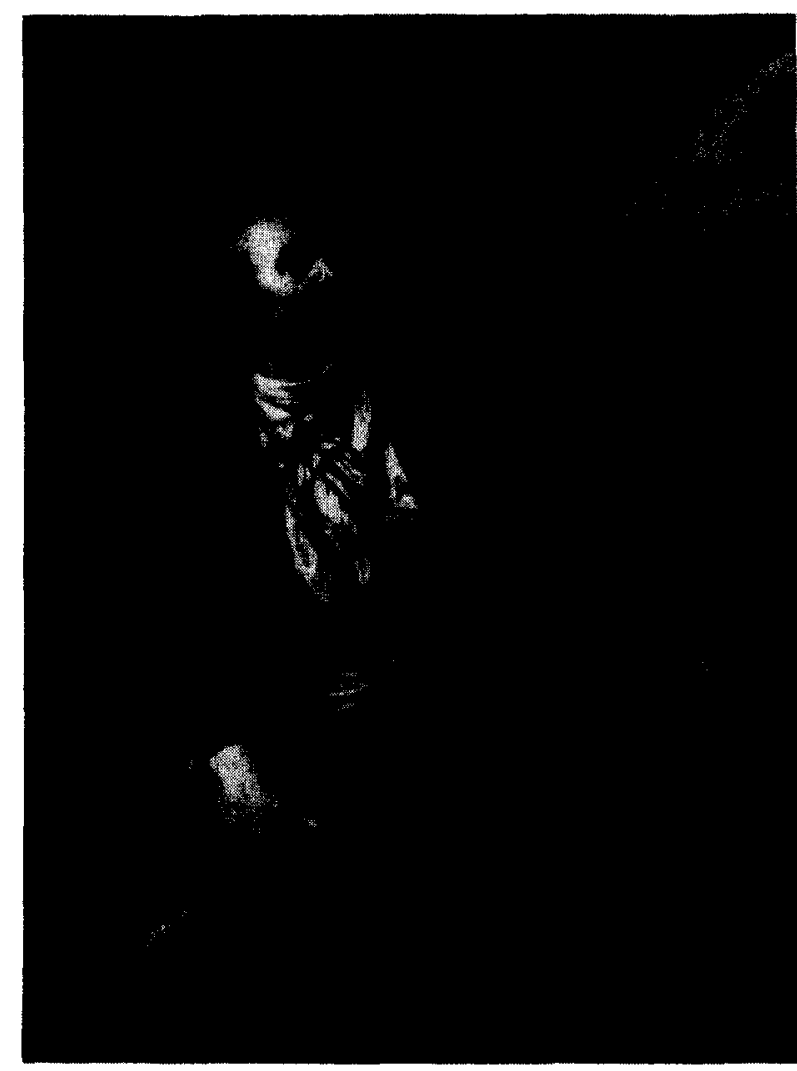

Fig. 2. Horace-Bénédict de Saussure, seated beneath an evergreen tree in the mountains. Beside him is a crystal specimen. In one hand he holds a rock, and in the other a geologist's hammer. Behind and to the right, in its rectangular frame, is the hygrometer he invented. Engraving by Charles S. Pradier after a portrait by St. Ours. [Bibliothèque nationale, Paris.]

al hero. (The new 20-franc note, put into circulation in 1979 , is dedicated to him.) His standing in Switzerland, as one of his country's first scientists of lasting international renown, is roughly comparable to that of Franklin in the United States, although Saussure was far more prolific and dedicated as a scientist, and much less important as a statesman, than was Franklin. See Fig. 2 for a copy of the romantic portrait by St. Ours. At the age of twenty-one Saussure competed unsuccessfully for the chair of mathematics at the Academy of Geneva. In the following year he gained the chair of philosophy, a post he was to retain until his retirement in 1786. At the Academy, Saussure lectured in French on physics and natural history and, in alternate years, in Latin on metaphysics. In his native city. of Geneva he was an energetic proponent of popular education and democratic reform. A passionate lover of mountains, he traveled and climbed often in the Alps, where he made extensive geological and meteorological observations and collected plants. In 1760, after making an unsuccessful attempt on Mont Blanc, Saussure posted notices around Chamonix offering a reward to the first person to climb the mountain. However, this feat was not accomplished until 1786, by Balmat and Paccard. In the following year, Saussure climbed the mountain himself, taking along a large party and a number of scientific instruments with which he made meteorological observations. He was the inventor of an electrometer and also of a hygrometer whose operative principle was the change in length experienced by a hair under tension when it is subjected to changes in atmospher- 
ic moisture. (Some modern hygrometers are still of this type.) His chief work was his Travels in the Alps, which treated the geology of his beloved mountains.

His student and successor, Marc-Auguste Pictet (17521825) came, like Saussure himself, from an established Genevan family. As a young man Pictet studied law at the Academy of Geneva and qualified as a lawyer in 1774, but already the sciences had begun to attract him. Pictet played an important part in the foundation of the Société des Arts at Geneva, and in 1778 published a treatise on meteorology in the second volume of the society's memoirs. When Saussure retired from the chair of philosophy in 1786, he helped to secure Pictet's appointment to the same position. A firm believer in the value of communication among scientists, Pictet was the joint founder and editor of two scientific journals, the Journal de Genève (1787-1791) and the Bibliothèque brittanique, which was founded in 1796 to keep European readers informed of British discoveries and publications. (In 1815 the journal dropped its exclusive interest in British science and was renamed the Bibliothèque universelle.)

Through most of his life, Pictet was active in public affairs. When, in 1798, Geneva lost its independence and was annexed by France, Pictet was one of the fourteen citizens charged with regulating conditions. A zealous Calvinist, he helped to ensure freedom of religion for his sect, succeeding so well as to gain more than was then accorded to the Catholic majority in France. Between 1802 and 1807 he served as a member of the French Tribunate. He gained a measure of influence in this assembly and was even named its secretary. However, he scarcely spoke except on matters of roads, canals, customs, and administration, and refrained from engaging in political debate. After Napoleon's fall in 1814, Geneva regained its independence, and Pictet was one of the city's first magistrates. ${ }^{10}$ The portrait of Fig. 3 presents Pictet as he appeared at about this time.

Pictet's scientific interests included meteorology, astronomy, and geodesy, but his most original and important research was a long series of experiments on heat, described in his Essay on Fire, ${ }^{11}$ to which we shall soon refer.

Saussure was interested in the phenomena of heat chiefly as they applied to meteorology and geology. His experiments on radiant heat are described in the second volume (1786) of his Travels in the Alps, in a chapter entitled, "The Causes of the Cold that Prevails on Mountains." Saussure mentions Lambert's experimental separation of light from heat using a glass lens and analogous experiments by Mariotte and Scheele. He therefore approves wholeheartedly Lambert's distinction between light and luminous heat on the one hand and obscure heat on the other. Saussure then describes another experiment, which he conducted himself and which provides an even clearer demonstration of this distinction.

An iron bullet, 2 in. in diameter, was heated red hot, then allowed to cool until it ceased to glow, even in the dark. It was then placed in the focus of a concave mirror of tin. A second similar mirror was placed about $12 \mathrm{ft}$. from the first one in such a way as to intercept the reflected rays. A thermometer placed at the focus of the second mirror began to rise almost immediately after the bullet was introduced at the first focus and continued to rise for about $6 \mathrm{~min}$, finally attaining a temperature more than $10^{\circ}$ above the starting temperature. ${ }^{12}$ Another thermometer, at the same distance from the bullet but out of the focus, suffered a much smaller rise.

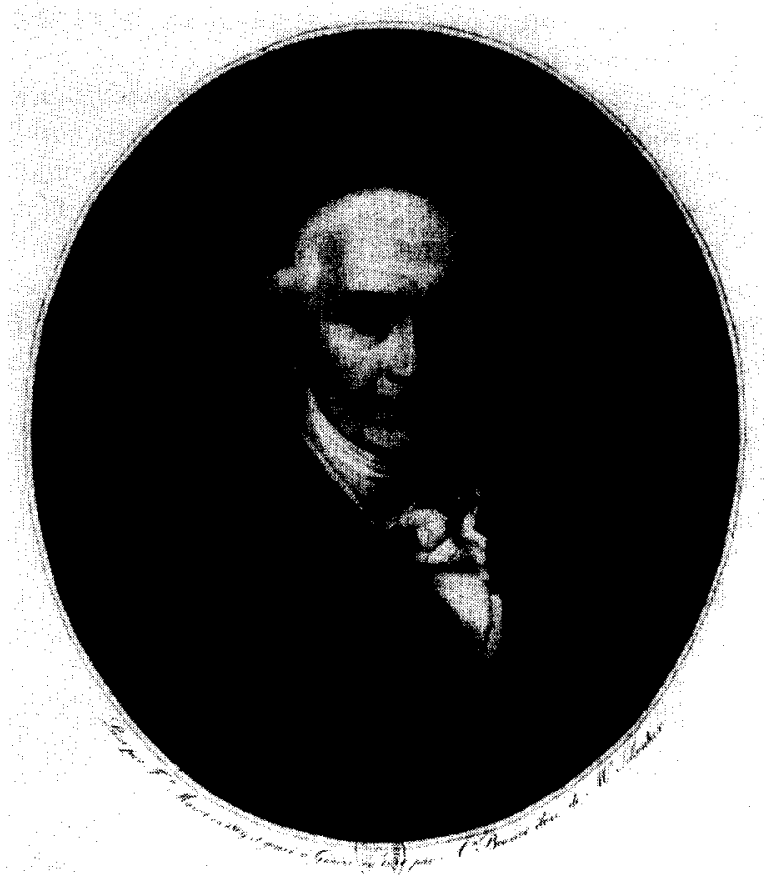

Fig. 3. Marc-Auguste Pictet, aged 57, nearly 25 years after his first experiments with radiant heat and cold. He appears here much as he must have when Rumford visited him in Geneva in 1804. Engraving made by $A$. Bouvier in 1821 after a painting done in 1809 by F. Massot. [Bibliothèque nationale, Paris.]

Saussure did not choose to pursue the matter further. As he says himself, he did not possess the apparatus necessary for the experiment, but borrowed what he needed from his colleague Pictet and performed the experiment with him. As was typical of all heat experiments in which Pictet had a hand, a good deal of care was taken with the arrangement. The experiment was conducted in a room with neither fire nor stove, and with doors, windows, and shutters closed as a precaution against accidental variations in the temperature of the air. It was clearly demonstrated, then, that the obscure heat that was collected and focused by the mirrors, and that caused the thermometer to rise, was quite distinct from light, for the bullet had been shown to emit the one and not the other.

Chapter 3 of Pictet's Essay on Fire is devoted to a sequence of experiments on the reflection, refraction, and absorption of radiant heat. Pictet begins with a description of the experiment with the bullet, performed jointly by Saussure and himself. In a second experiment, Pictet replaced the bullet at the focus of the first mirror with a lighted wax taper. Again, a thermometer at the focus of the second mirror showed a considerable rise. As Pictet remarks, in the action of the bullet there was only pure heat without light, while in the action of the taper there was a mixture of heat and light.

Pictet therefore thought of separating the two causes in the usual way, by interposing a transparent plate of glass midway between the mirrors. This glass, which allowed the light to pass through apparently undiminished, proved to be but imperfectly permeable to the heat. After the burning taper had caused the thermometer to rise through more than $10^{\circ}$, the interposition of the glass allowed the thermometer to descend through more than half of this distance. When the glass was removed, the thermometer again ascended to about its former level. 
Pictet felt, as he says, some scruples regarding the experiment with the bullet. It might have been the case that, although the bullet did appear perfectly dark, it could yet be luminous to organs more sensitive to light than the human eye. He felt he could be more certain of employing a hot but not luminous body by substituting a glass matrass of boiling water. The results were essentially the same. It appeared beyond doubt that radiant heat was susceptible to being reflected and that, while it obeyed the same laws as light, it was something quite different from light.

\section{Radiation and reflection of cold}

Pictet happened to discuss his experiments with Louis Bertrand, ${ }^{13}$ professor of mathematics at Pictet's own Academy of Geneva. Bertrand asked Pictet whether he believed that cold also could be reflected. Pictet's response, as he recorded it himself, was immediate and negative:

$\mathrm{He}$ [Bertrand] asked me if I believed cold susceptible of being reflected? I confidently replied no; that cold was only privation of heat, and that a negative could not be reflected. He requested me, however, to try the experiment, and he assisted me in it.

The apparatus was arranged as shown in Fig. 1. Two mirrors of tin were placed $10 \frac{1}{2} \mathrm{ft}$ apart.

At the focus of one was a thermometer of air, which was observed with the necessary precautions, and at the focus of the other a matrass full of snow.

At the instant the matrass was placed for experiment, the thermometer at the opposite focus descended several degrees, and remounted as soon as the matrass was removed.

Having replaced the matrass at the focus, and thus made the thermometer descend to a certain degree, where it remained stationary, I poured some nitrous [i.e., nitric] acid upon the snow, and the cold thus produced caused the thermometer to descend instantly 5 or $6 \mathrm{deg}$. lower.

The fact was notorious, and amazed me at first; a moment's reflection, however, explained it. This phenomenon offered nothing more than a final proof, if it had been necessary, of the reflection of heat... ${ }^{14}$

How Pictet accounted for his astonishing result, we shall presently see. But first we must briefly turn our attention to certain academicians of Florence who anticipated his experiment, and to Rumford who used it as a point of departure.

\section{Pictet anticipated}

Some time after making his discovery of the existence and reflectibility of cold emanations, Pictet learned that he had been anticipated by more than a century. For, as he writes in the Essay on Fire, "The academicians, del Cimento, have endeavored to concentrate cold at the focus of a concave mirror. But they acknowledge that their experiments had been made in a manner not sufficiently exact to authorize any conclusion." 15 The Accademia del Cimento, or Academy of Experiment, was founded in Florence in 1657 by Prince Leopold de 'Medici, brother of the reigning Grand Duke Ferdinand II of Tuscany. The academy flourished for a brief while, but ceased to exist within ten years of its founding. It produced but one publication, the sumptuous volume Saggi di naturali esperienze (Florence, 1667).
Among the accounts of a series of "Experiments on Natural Ice," we find the following:

\section{The Ninth Experiment}

The desire came to us to find out by experiment whether a concave mirror exposed to a mass of 500 pounds of ice would make any perceptible reverberations of cold in a very sensitive 400-degree thermometer located at its focus. In truth this at once began to descend, but because the ice was nearby it remained doubtful whether direct cold or that which was reflected cooled it most. The later was taken away by covering the mirror, and (whatever the cause may have been) it is certain that the spirit immediately began to rise again. For all that, we shall not dare to affirm positively that this could not at that moment have resulted from something else besides the lack of reverberation from the mirror, as we have not repeated all the tests that would be needed to be perfectly sure about the experiment. ${ }^{16}$

It was no doubt through this account that Pictet learned of the experiment of his predecessors. Pictet has little to say of them beyond what they admitted themselves, that they could not be completely confident of their result. Rumford, on the contrary, was hard-probably too hard-on the academicians for their incredulity, which he supposed was only due to prejudice:

...it is not a little curious, that the learned academicians who made the experiment, and who made it with a direct view to determine the fact in question, were so completely blinded by their prejudices respecting the nature of heat that they did not believe the report of their own eyes; but, regarding the reflection and concentration of cold (which they considered as a negative quantity) as impossible, they concluded that the indication of such reflection and concentration which they observed must necessarily have arisen from some error committed in making the experiment.

Happily for the progress of science, the matter was taken up...by Professor Pictet; and the interesting fact, which the Florentine academicians would not discover, was put beyond all doubt. ${ }^{17}$

In fairness to the academicians, it should be pointed out that they do not appear obviously to reject the result of their experiment for the motive Rumford attributes to them. No doubt, they did regard cold as a negative, i.e., as the privation of heat, for that was the prevailing view. However, they seem to have been at least as strongly troubled by the inadequacies of their equipment. As they used a spirit thermometer, it almost certainly lacked the sensitivity required to make the effect perfectly evident. The authors of the present article, who have repeated Pictet's experiment with home-made equipment, initially had a hard time convincing themselves that the effect was genuine and not due to convection cooling. The introduction of a sensitive air thermometer made all the difference, as it permitted the removal of the cold object to a much greater distance.

In any case, Pictet made his discovery independently of the Florentines and his methods left no doubt about the reality of the effect. After his announcement, the experiment was often repeated and provoked a lively international discussion. If a name is to be attached to it, it is his that belongs. Certainly, Rumford never spoke of the reflection and concentration of cold by curved mirrors otherwise than as "Pictet's experiment." 18 


\section{E. Rumford's research on frigorific rays}

Rumford appears first to have learned of Pictet's experiment in London in 1795 or 1796 . (Pictet had published his results in 1790, but Rumford had passed the first half of the 1790 's in the relative isolation of Bavaria, where he served the elector Carl Theodor in several different capacities.) In the winter of 1796-1797, Rumford made a crude attempt to detect the existence of cold radiation by placing cakes of ice near a sensitive thermometer, but observed no effect. Rumford corresponded on the matter with Pictet, who was puzzled by the negative result. ${ }^{19}$ Through the remainder of the decade the two maintained a regular correspondence and Rumford habitually sent Pictet copies of his writings, some of which Pictet used for the Bibliothèque britannique. The two men seem always to have remained on the best of terms-a fact that must be attributed to Pictet's accomodating nature, for Rumford managed to keep very few friends.

As mentioned at the beginning of this article, Rumford first saw a successful replication of Pictet's experiment at the house of Thomas Hope in Edinburgh in October, 1800. Hope first repeated the experiment exactly as Pictet had described it, using the arrangement shown in Fig. 1. Rumford then introduced various changes, in order to remove all suspicion about the reality of the effect. Two days later, he wrote to Pictet to report the confirmation of Pictet's result.

Rumford had already projected a series of experiments on radiant heat, and the remarkable demonstration of the radiation and reflection of cold determined him not to put off this intention a moment longer. As soon as he returned to London, in the fall of 1800 , he began to make preparations, including the acquisition of four large metallic concave mirrors and other apparatus. As Rumford says himself, the principal goal of his projected investigation was to establish beyond doubt the existence of cooling emanations from cold bodies. However, the construction of the equipment entailed a long delay, and some time passed before he was actually able to begin his experiments. ${ }^{20}$

In the summer of 1801, Pictet came north to make a tour of Ireland, England, Scotland, and Wales. In the course of his travels he wrote, for the Bibliothèque britannique, a series of 12 long letters which contain an entertaining mix of geological observations and speculations, anecdotes of the road, and descriptions of English manufacturing and agriculture. ("A propos of turnips, I asked for some details on the rutabaga.") Pictet offered also a few observations on English life and manners, and even provided occasional advice to future travelers. (For example, he denounced the inn of Chester, where he supped, as one of the worst and most expensive in England.) Pictet began and ended his tour of Britain at London, where he stayed with Rumford as a house guest.

The two had many long conversations, on a wide variety of subjects. Pictet was very much impressed with the count and took notes immediately after each conversation, in order not to lose anything if he could help it. No doubt they talked once or twice of the radiation and reflection of cold. But Rumford's favorite subject of conversation always was himself, and he treated Pictet to many long autobiographical reminiscences. These Pictet seems to have encouraged, both because he was an admirer of Rumford's scientific work, and because he found Rumford's stories genuinely interesting. "What a life he has had!" Pictet exclaimed.
And it was true - there are many strange lives from the eighteenth century, but few are stranger than Rumford's. When the truth, remarkable in itself, was heightened by Rumford's habitual exaggeration, it made quite a story indeed. Pictet pressed Rumford to write his memoirs. Rumford declined, but he allowed Pictet to write a biographical notice for publication in the Bibliothèque brittanique.

During Pictet's stay in England, the British government placed an embargo on all direct communication with France, except by letter. Consequently, Pictet found himself stranded, with no easy way of returning to the Continent. He stayed on for several more weeks as Rumford's guest, and used his time in seeing the sights of the London area, visiting the workshops of artists and craftsmen, and acquiring a collection of British scientific instruments. Rumford took him on several outings: a trip to Woburn Abbey to see the gardens and farms of the Duke of Bedford; a tour of an English brewery; and a visit to Richmond Park to see some kangaroos from Botany Bay.

The embargo continued. But Rumford, who had business to attend to in Bavaria, managed to obtain passports for both Pictet and himself. The two crossed together on 20 September 1801 from Dover to Calais, where they parted company. ${ }^{21}$

Rumford hurried on to Munich, arranged his affairs there, and left almost immediately for Paris. Rumford had intended to make only a quick stop in Paris before returning to London. But, as a result of his unexpectedly warm reception by the French scientific community, and also his growing infatuation with Madame Lavoisier, the widow of the distinguished chemist, Rumford stayed on in Paris for nearly two months.

On 8 November 1801, Rumford dined with Bertholet in Arceuil. The conversation came around to the theory of heat. Rumford noted in his diary, "...we had some friendly altercation respecting caloric which however made no converts. Bertholet thought we could explain Pictet's experiment on the reflection of cold in a manner perfectly satisfactory but we convinced him at last that the matter was by no means so clear as he had imagined it to be."

Not long afterwards, Rumford met Albertine Necker de Saussure, ${ }^{22}$ the married daughter of the Swiss physicist, and conversed with her on, among other things, Pictet's experiment. He found her "uncommonly well informed. She gave me the best explanation I had ever heard of the curious phenomenon of the reflection of cold. My explanation and hers differ only in the meaning of the words. She supposes obscure heat to be emitted by all bodies and I suppose invisible rays to be emitted which though not hot themselves are the cause of heat in other bodies. These rays I suppose to be merely undulations in the etherial fluid."23

In December, Rumford returned to England to straighten up affairs and departed again for the continent in the following May. After a second stay of nearly three months in Paris, Rumford reached Munich in August, 1802. Nearly two years had elapsed since he had seen Pictet's experiment performed in Edinburgh. He had begun his own experiments in London, but because of all his traveling, as well as delays by the workmen in the construction of his apparatus, he had actually accomplished very little. In Munich, in early October, 1802, he took up his investigation in earnest.

Unfortunately, he had not been able to bring the four large metallic reflectors with him from London. (The Royal Institution had financed their construction and retained 
possession.) As he could not obtain similar ones in Bavaria, he was forced to find methods of investigating hot and cold emanations without the aid of the concentration brought about by means of the reflectors.

It would take too much space to describe Rumford's investigations in any detail. His own account is quite clear and is, moreover, easily accessible. There are, however, a few points that must be made, as they bear directly on our story.

In one series of experiments, Rumford filled two identical metal containers with warm water and allowed them to cool while exposed to the air. He covered one of these containers with a layer of fine Irish linen; the surface of the other was polished clean and bright. He found that the vessel covered with linen cooled much more quickly. Rumford was keenly interested in the insulating qualities of clothing, and it is likely that he first wrapped linen around his cylinder with this interest in mind. If so, the result of the experiment must have been a shock. Nevertheless, Rumford concluded that the linen must somehow have accelerated the cooling - either by facilitating the approach of a succession of fresh particles of cold air, or by increasing the effects of radiation.

To discover which of these processes was responsible, Rumford next applied a thin layer of glue to one of the metal vessels. The coating of glue, which completely excluded the air, could hardly be considered to improve the contact between the metal and the air. And yet the gluecoated vessel cooled much more quickly than an identical vessel whose metal surface had been left naked and highly polished. When Rumford applied a second coat of glue to the first vessel, he found that the speed with which it cooled was again increased. In a similar set of experiments with varnish, Rumford found that the cooling rate increased when additional coats were applied, up to a total of four, after which the cooling rate began to decrease. And, again, he found that a thin layer of soot, which weighed almost nothing, greatly increased the rate at which the metal vessels cooled. ${ }^{24}$ The inescapable conclusion was that the soot, the varnish, the glue, and the linen all somehow acted to increase the emission of calorific rays from a hot surface. Moreover, the complementary, or even equivalent, natures of heat and cold were nicely demonstrated by filling the same vessels with cold water rather than hot. The same coatings that had been found to accelerate the cooling of hot bodies also facilitated the warming of cold bodies.

In a second series of experiments, Rumford employed the thermoscope, an instrument of his own devising (see Fig. 4). This consisted essentially of a sealed glass tube with

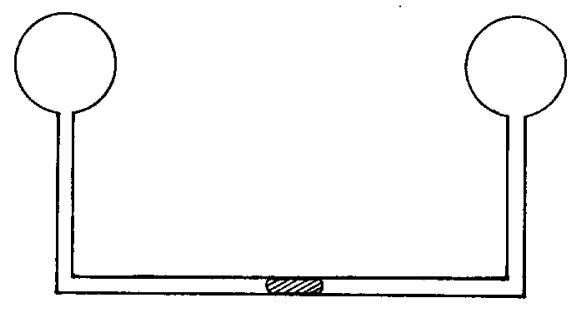

Thermoscope

Fig. 4. Rumford's thermoscope. upbent ends that terminated in hollow balls. A small quantity of colored alcohol or other fluid lies initially at the middle of the horizontal part of the instrument. If a warm metal cylinder is brought near one of the glass balls of the instrument, the calorific rays absorbed by that ball will cause the air at that end of the instrument to expand, and the bubble of fluid will be displaced towards the opposite end of the thermoscope. A cold metal cylinder, brought near one ball of the instrument, will, contrarily, draw the bubble nearer. Rumford remarks that the results of these experiments afford indisputable proof of the radiation of cold bodies, and that the rays which proceed from them have a power of generating cold in warmer bodies that are exposed to their influence.

Rumford next sought to establish whether the power of frigorific rays to affect their surroundings was or was not equal to the power of calorific rays. For this, the following simple experiment was decisive. The thermoscope was at room temperature, $72{ }^{\circ} \mathrm{F}$. Rumford presented to one of its balls, at a distance of 3 in., the flat end of a metal cylinder filled with ice water. At the same moment, an assistant presented to the opposite side of the same ball of the thermoscope, and at the same distance, an identical cylinder filled with warm water at the temperature of $112^{\circ} \mathrm{F}$. The one cylinder was at $32^{\circ} \mathrm{F}$, or $40^{\circ}$ below room temperature; while the other was $40^{\circ}$ above room temperature. The bubble in the thermoscope did not bulge, but remained absolutely stationary. If, however, the cold body was removed a little farther from the ball (to the distance of $3 \frac{1}{2}$ in.) while the hot body remained at $3 \mathrm{in}$., the bubble in the thermoscope responded immediately. Rumford concluded that, "At equal intervals of temperature, the rays which generate cold are just as real, and just as intense, as those which generate heat; or, that their actions are equally powerful in changing the temperatures of neighbouring bodies." 25

He now blackened the ends of both cylinders and repeated the experiment. Again, the bubble of the thermoscope did not budge, although the warm cylinder was now known to be emitting rays much more strongly than before. Rumford concluded that "those circumstances which are favorable to the copious emission of calorific rays from the surfaces of hot bodies are equally favorable to a copious emission of frigorific rays from similar bodies when they are cold." And, of course, Pictet had established beyond doubt that frigorific rays could be reflected and focused in the same way as calorific rays. In fine, frigorific and calorific rays obeyed exactly the same laws.

Rumford completed these investigations early in the spring of 1803, and in May he finished writing a memoir on the subject. In June, Madame Lavoisier arrived in Munich and the two of them left for a journey into Switzerland, taking along Rumford's memoir and some of his newly invented instruments. Pictet met them en route, led them on a tour of the glaciers above Chamonix, and finally escorted them to Geneva. In Geneva, in August, Rumford read the memoir and repeated some of the experiments with the thermoscope before a group of Swiss scientists. Among the audience were Senebier, Nicolas-Théodore de Saussure (son of H.-B. de Saussure, who had died in 1799), and Marc-Auguste Pictet-this, nearly 20 years after Pictet's discovery of the existence and reflectibility of cold emanations. Pictet translated the memoir into French, and it was this translation that appeared in Rumford's Mémoires sur la chaleur, published in Paris and Geneva in $1804{ }^{26}$ 


\section{THEORIES OF RADIANT HEAT AROUND 1800: EXPLANATIONS OF PICTET'S AND RELATED EXPERIMENTS}

Pierre Prevost, writing around 1818 , remarked that the opinions of physicists on the nature of light naturally divided them into three classes: "les émissionaires, les undulateurs, et les indifferens." 27 A similar division applies very well to physical doctrines on the nature of heat during the 30 -year period that concerns us here (1775-1805). If anything, opinion on heat during this period was even more fragmented. Reduced to its most basic terms, the question was this: were the phenomena of heat produced by emissions of a material substance, or were they due to undulations?

The views of the eighteenth-century undulateurs should be carefully distinguished from modern thermodynamics, which they but little resembled. To be sure, certain phenomena of heat were sometimes ascribed to the vibrations of the individual atoms and molecules that made up macroscopic objects. But, just as often, the discussion centered on the undulations, or waves, that were supposed to propagate through an all-pervading subtle fluid. This fluid, known in the 1770's as fire, or the igneous fluid, was after Lavoisier's introduction of the term caloric in 1787 sometimes called by that name as well. This expropriation by the undulationists of a technical term usually associated with emissionist theories somewhat blurs the distinction between the two camps. The igneous fluid was held by some to be continuous and by others to be discrete. Its undulations served to couple the individual atoms of macroscopic objects and thus accounted for the propagation of the vibratory disturbance that was heat through solids, liquids, and gases. Again, it was the undulations of the igneous fluid that accounted for the transmission of heat through a vacuum. ${ }^{28}$

The emissionists, on the other hand, asserted that the phenomena of heat were due to the emanation of a material substance by hot objects and its absorption by cold objects. This substance, sometimes known as fire, sometimes as heat or matter of heat, came finally to be called caloric. (Again we must point out the considerable overlap in the technical vocabulary of the emissionists and the undulationists.) The substance of heat was known to be extremely light and was generally believed to be discrete, i.e., made up of atoms or molecules. But there all agreement ended. Scheele, in 1777, complained of the multiplicity of views on the nature of fire and light and the instability of the technical vocabulary:

Sometimes heat is fire, sometimes light is fire. And sometimes heat is elementary fire, or again it is an effect of fire. Sometimes light is the purest fire and is an element; or, again, it is spread out through the whole extent of the globe and its motion in a straight line is communicated to it by the impulsion of the elementary fire; or, yet again, light is an element that can be captured by means of the acidum pingue, and that is liberated by the dilation of this supposed acid, etc. ${ }^{29}$

Scheele, as we have seen, believed that a molecule of heat was a loose association of an atom of oxygen and a little phlogiston. (Fire, of course, meant something else to him.) Contrast this theory with the theory of De $\mathrm{Luc}^{30}$ - to take an influential writer of the Swiss school. According to De Luc, fire (by which he meant what Scheele called heat) was composed of light and matter of fire, this last being a sub- stance which had some weight but whose other properties were unknown and which had never yet been found in separation from light. Again, as we have seen, Scheele held that heat was essentially the same as radiant heat and light, and differed from them only in its phlogiston content. De Luc, on the other hand, classified fire as an elastic vapor: as a union of light and matter of fire, fire was strictly analogous to water vapor, which was produced by the union of fire and water. And, of course, there were others (e.g., Buffon) who considered fire to be an element and therefore irreducible. ${ }^{31}$

Such was the climate of thought in which Pictet and his contemporaries sought a theory of radiant heat that would explain the reflection of cold and allied experiments. There were, indeed, but two main camps, the undulationists and the emissionists; but each of these groups was fragmented into many smaller ones.

In the previous section, we described several closely related experiments performed by Saussure, Pictet, and Rumford. We shall now examine the theoretical explanations of the new phenomena that were offered by these same three writers, together with the theory of Pierre Prevost, a friend of Pictet's in Geneva. In this way, we shall arrive at a better understanding of the meaning of the experiments themselves for the physicists who first performed them. Moreover, by examining the opinions of four physicists on more or less the same questions, we shall get a cross-sectional view of the emissionist-undulationist debate. In Saussure and Pictet, we shall see a cautious undulationist and a cautious emissionist, respectively. But in Rumford and Prevost, we shall see two of the most confident and assertive proponents that the two schools of thought ever produced.

\section{A. Saussure}

As mentioned above, Saussure was interested mainly in geology and meteorology. His account of the experiment with the bullet and mirrors, performed jointly by Pictet and himself, appears in the course of a discussion of the cold that prevails on mountain summits. Saussure points out that a number of attempts had been made to explain the decrease of atmospheric temperature with altitude, and summarizes the opinions of two notable physicists, Lambert and De Luc. Saussure, however, expresses serious doubts about both theories. He then produces his demonstration of the reflectibility of radiant heat mainly as evidence against the theory of De Luc.

According to De Luc, fire is a fluid, both elastic and continuous, which is capable of compressing under its own weight, in the same fashion as the air itself..$^{32}$ The temperature of the air at a given altitude depends on the density of the fire at that altitude. Hence the higher temperatures at the lower elevations, where the fire is denser.

Against this tidy system Saussure offers his evidence of the reflection of obscure heat and its concentration at the focus of a mirror. If heat were a continuous fluid, could it really behave in this way? It is impossible to conceive that a torrent of this fluid, pressed from all sides by the mass of the same fluid which surrounds it, could be reflected and concentrated at the focus of a mirror. After all, it would be absurd to suppose that a current of air, put into motion in the midst of the atmosphere, would be focused by reflection from a mirror. Rather, it would be scattered to all sides. Thus, if heat is to be regarded as a continuous fluid, the 
mirror experiments cannot be explained by supposing a transport or emanation of the substance of fire.

According to Saussure, the continuous fluid theory can only be maintained if we suppose that what we call heat in a body depends on a certain agitation of the igneous fluid, locked up in the pores of the body, and that this agitation is communicated by oscillations that one could call calorific. Such oscillations are capable of being reflected, exactly as are the undulations of sound. The mirror and bullet experiment, says Saussure, is very important as it demonstrates that heat can be excited not only by an accumulation of the igneous fluid, but also by its vibrations or oscillations. Saussure thus seems to accept the existence of fire as a continuous fluid filling the whole of the space in which the experiment was conducted. The mirror experiment is not, however, to be explained by a transport of the fluid itself, but rather by a vibration in the fluid.

Saussure next takes up the alternative hypothesis, that heat is not a continuous but rather a discrete fluid, like light. In this case, radiant heat could be regarded as a stream of igneous molecules, which, without having the speed necessary to excite the sensation of light, would nevertheless travel in straight lines and be susceptible of being reflected and concentrated in a focus. This hypothesis, however, is not very favorable to De Luc's system. For if fire were a discrete fluid, its particles would be separated from one another and, according to Saussure, could not press on one another; nor could they be condensed by their own weight. Consequently, one could not deduce the decrease in the density of fire with altitude that is necessary to explain the decrease of atmospheric temperature.

After pointing out several other difficulties with the theories of De Luc and Lambert, Saussure declines to engage himself any further with questions concerning the nature of fire and light. He remarks that, if simple and universally accepted principles will account for the diminution of the heat on the mountain summits, there is no reason to introduce hypotheses that are the least bit doubtful. He then expresses approval of Bouguer's ${ }^{33}$ explanation of the cold that reigns on the summits: First, the sun can strike a mountain's faces only for a few hours each day, contrary to the case on a horizontal plane. Second, on account of its transparency, air is not appreciably heated by direct absorption of the sun's rays; and this is even more true in the upper altitudes, where the atmosphere often possesses a singular transparency. Third, and finally, the air at lower elevations is warmed by the contact or proximity of the Earth, an effect that is greatly diminished on mountain summits and isolated heights. ${ }^{34}$

\section{B. Pictet}

In several places in his Essay on Fire, Pictet remarks on the equivalent explanatory power of the caloric and the wave theory of heat: it was not possible to choose between the two on the basis of experimental evidence. However, he inclined by personal preference to the caloric theory, which had been championed by the French physicists and chemists, and notably by Lavoisier.

As regards the apparent radiation and reflection of cold, Pictet had been initially astounded by the results of his own experiment. However, after a moment's reflection, he felt able to explain it. Refer to Fig. 1.

Pictet treats first the equilibrium case, in which both foci are occupied by objects at room temperature. Thus, at the focus of mirror $A$, instead of a flask of snow or hot water, we are to imagine a quantity of air at room temperature. And at the focus of mirror $B$, we place a thermometer, also at room temperature. Obviously, the temperature of the thermometer will not change. But what is the physical process that lies behind this fact of observation?

If the thermometer were raised in temperature, no matter how little, it would have to be considered as a heated body, relatively to every colder body. Its fire would tend therefore to leave it and, if it could, would diffuse itself around the thermometer in the form of a radiant emanation, a considerable part of which would be reflected to $A$ 's focus. But this effect is only potential because the air at the focus of mirror $A$, now supposed to be at the same temperature as the thermometer, will develop the same tension as the fire in the thermometer at the opposite focus. The air at the focus of $A$ will therefore resist the escape of heat from the thermometer with a force precisely equal to that which the fire in the thermometer will exert to arrive at the focus of $A$. "In this case, then, everything is in equilibrium, and the fire cannot move, because the resistance is on all sides equal to the tension." Pictet thus regards the equilibrium situation as a static balance of tension and resistance. Neither object is able to emit or to receive radiant fire.

Having thus clarified several fundamental ideas, Pictet is prepared to take up the reflection of cold. Suppose now that, instead of the room-temperature air, we place at the focus of mirror $A$ a cold body, such as ice or snow, that is of such a nature as to destroy entirely the tension of any fire that arrives there. In this case, the transport of fire out of the thermometer, which previously was only potential, would become actual. The presence of the cold body would open a kind of gulf to the heat of the room. It would all the more readily absorb the heat of the thermometer, as that heat would arrive by a kind of funnel. Mirror $B$, because of its size and placement, would receive about a third of the calorific emanation coming from the thermometer, which it would reflect to mirror $A$, after which the heat would be entirely lost in the matrass of snow at the focus of $A$. As Pictet remarks, this arrangement is extremely advantageous for depriving the thermometer of its heat, compared with the direct effect of the same quantity of snow at an equal distance.

Pictet concludes his explanation with the observation that the experiment performed with snow does not differ from that performed with the bullet or the matrass of boiling water, except as regards the direction in which the calorific emanation moves. In the latter case, it moves from the bullet or the matrass of boiling water to the thermometer; i.e., from the focus of $A$ to the focus of $B$. In the experiment performed with snow, it moves in the reverse direction, i.e., from the thermometer to the matrass of snow. Thus the thermometer stands in the same relation to the snow as the bullet to the thermometer.

Finally, Pictet remarks that the same explanation will apply if we regard the caloric effect as resulting, not from a real emanation, but from a vibration in the elastic fluid of fire that fills the space in which the experiment was performed. "It is known that these vibrations are susceptible of being reflected according to the same laws as emanations, of which the reflection of sounds affords us daily examples."35 


\section{Prevost}

A year after the appearance of the Essay on Fire, Pictet's friend and colleague Pierre Prevost (1751-1839) published a remarkable treatise on thermal equilibrium by means of simultaneous exchanges of heat particles. Prevost's theory, conceived almost entirely as a means of accounting for the apparent radiation and reflection of cold, was one of the most remarkable achievements of the emissionist school of thought during the eighteenth century.

Prevost's career was extraordinarily varied, even by eighteenth-century standards, and he earned a measure of distinction in several different fields. As a young man he did three-and-a-half years of theology, but threw that over for the study of law. He qualified as a lawyer at Geneva in 1773, one year in advance of Pictet. Prevost seems to have had as little taste for law as for the ecclesiastical life, for he did not enter into practice but accepted posts as a private tutor, first in Holland and later in Paris. While at Paris he published the translations of the tragedies of Euripides that established his reputation.

In 1780 he accepted from Frederick II, the king of Prussia, a place in the Academy of Berlin and the chair of philosophy in the college of nobles. It was at about this time that Prevost produced his first works in political economy. Besides original studies, he published translations of works by Adam Smith, Malthus, and Benjamin Bell.

In 1784 , drawn back to Geneva by the last illness of his father, Prevost accepted the professorship of belles-lettres at the academy. But he surrendered this position in the following year in order to devote his attention to the edition of the Greek classics that Cussac was publishing in Paris. Upon his return to Geneva, Prevost threw himself into physical researches and in 1788 published a book on the origin of magnetic forces. In 1791 he published his explanation of Pictet's experiment and, in the following year, a book of Physico-mechanical Researches on Heat. In 1793 he won the competition for the chair of philosophy at the Academy of Geneva.

Prevost thus became Pictet's colleague in the faculty of sciences and shared with him the teaching duties in several branches of the physical sciences. In philosophy proper, Prevost devoted himself especially to logic. He was also an admirer of the Scottish school and translated the first part of the Elements of Philosophy of Dugald Stewart, with whom he kept up an active correspondence. Prevost entered briefly into public affairs at all the critical junctures of Geneva's political development, in 1793, in 1798, and again in $1814 .^{36}$

Pictet, as we have seen, explained his radiation experiments, including the apparent reflection of cold, in terms of the notion of thermometric tension. (This concept, rather popular in the 1780's, had been championed notably by Volta.) Thus the equilibrium situation, in which objects of equal temperatures occupy the two foci, is a case of static equilibrium. The expansive force of the radiant fire at the one focus exactly balances that at the other, and neither object is able to emit or to receive radiation. Pictet discussed his experiments with many of his colleagues. But when he related his discovery of the reflection of cold to his friend de Végobre, ${ }^{37}$ the latter perceived a flaw in his explanation of the phenomenon. It was de Végobre who remarked to Pierre Prevost that Pictet's experiment had not been satisfactorily explained.

Now Prevost, like everyone else at Geneva, was thor- oughly familiar with the theory of discrete fluids of G.-L. Le Sage. ${ }^{38}$ Consequently, he was disposed to assume that nearly all physical phenomena-heat, light, electricity, and even gravity-were explicable in terms of discrete fluids. Prevost saw immediately that the apparent radiation of cold ought also to be explicable in such terms and set himself the task of constructing the explanation. The job proved harder than he had imagined, but he succeeded at last and produced his very interesting "Memoir on the Equilibrium of Fire." ${ }^{39}$ Here, as we shall see, Prevost introduced a mode of reasoning that has since become habitual in thermodynamics.

Prevost asserts that fire is a discrete fluid. If this much is granted, it will be possible to explain all the phenomena of equilibrium, many of which would otherwise be unexplained.

Prevost next points out that Pictet's explanation of the reflection of cold in terms of thermometric tension is inconsistent with the true nature of fire. A discrete fluid whose particles can radiate, like light, can be contained by partitions, but cannot be contained by another radiant fluid, nor, consequently, by itself. A beam of light, after all, can cross through another beam without disturbing it in the least. Similarly, radiant fire moves freely through fire, which is present everywhere on Earth; and since it does not suffer any sensible perturbation, its particles must be separated by intervals large compared to their diameters. This fact is inconsistent with the commonly held view that fire is coercible by itself and that quantities of fire in two contiguous portions of space mutually contain one another when their temperatures, or their tensions are equal. In reality, the fire of one portion cannot halt that of another; rather, they give one another free passage. It is therefore false to say that two contiguous portions of fire contain one another mutually like two compressed springs in contact.

In what, then, does thermometric equilibrium consist? According to Prevost, such equilibrium between two bodies consists in the equal, simultaneous exchanges of fire particles between them. Imagine two cubical portions of space which share a common face, thus forming a rectangular parallelepiped. Let the walls of this rectangular box be of a material perfectly solid and poreless. Into this box, Prevost imagines placing a quantity of free fire. The fire moves freely through the whole of this space. And there is no reason why it should pass with less facility through the empty square that is the boundary between the two cubes than through any other part of this space. There are continual exchanges of particles between the two portions but the quantity of fire in each remains constant. Different particles are ceaselessly found in the same place, but their number and their average separation remain constant. Such is the state of thermometric equilibrium.

Now suppose that one disturbs the equilibrium by adding to one of the two portions of space some new fire: for example, a tenth of all that which was contained in that portion. This fire soon spreads into all the space that it can penetrate freely. Thus the exchanges between the two portions will be unequal. One portion will send to the other 11 particles, while the latter will send it only ten. This state constitutes the rupture of the equilibrium between the two portions. But because of the unequal exchanges, the equality will quickly be re-established.

At this juncture, Prevost quotes the result of an unpublished calculation performed by Le Sage some 30 years before. (Le Sage dug the manuscript out from among his pa- 
pers when Prevost happened to mention his new theory of thermal equilibrium.) Suppose that the densities of the fire in the two cubical spaces are as the numbers 1 and 2, i.e., that the one is twice as warm as the other. Suppose further that in $1 \mathrm{~s}$ there passes from one cube to the other a number of fire particles which is to the total as 1 is to 10 . Then, according to the calculation of Le Sage, after $7 \mathrm{~s}$ the densities of fire in the two cubes will be as 5 is to 6 . After $14 \mathrm{~s}$, these densities will be as the numbers 28 and 29, i.e., very close to equality. The equilibrium will appear to have been re-established. Le Sage had made this calculation long before, and with discrete fluids in mind quite different from radiant fire. But Prevost found in it a nice illustration of the approach to equilibrium for any radiant, discrete fluid, and adapted it for his own use.

With the general principles of his theory now explained, Prevost takes up the particular phenomenon that aroused his interest in the first place-the reflection of cold. We are to imagine two concave spherical mirrors opposed to one another along their common axis, as in Fig. 1. Two identical bodies are placed in the foci. Prevost considers first the equilibrium case. The two bodies are at the same temperature, i.e., they throw, each against its own mirror, equal quantities of radiant fire in equal times. Each of the two bodies receives from the other precisely as much as it sends to it. Immanation compensates exactly for emanation.

Now Prevost proposes to alter the temperature of one of the two bodies. The exchanges that are made between them by means of the double reflection will cease to be equal and the equilibrium will be broken. Suppose, for example, that we subtract fire from the first body, say one tenth of the total. The second body will have unfavorable exchanges with it, receiving nine particles for every ten that it sends, and will thus become colder. And there, according to Prevost, is the true explanation of the apparent reflection of cold, a phenomenon that would be inexplicable without the theory of discrete fluids. Indeed, there is little to fault in Prevost's explanation. For the sake of simplicity (as he says himself), he ignores the very important role of the environment and considers only the heat exchanges between the two bodies in the foci. But it is clear that the exchanges between these bodies and the environment could easily be taken into account.

Prevost rounds out his article with a second demonstration of the inadequacy of Pictet's explanation of the reflection of cold in terms of thermometric tension. Prevost argues that, both by the direct action of the ice and by the mechanism of the double reflection, the thermometer $(D$, in Fig. 1) is more cooled than its mirror $(B)$. The fire in the thermometer is thus in lower tension than the fire in its mirror. Hence, according to the old theory, fire cannot pass from the thermometer to its mirror; nor, consequently, can it radiate from there to the opposite mirror and thence to the ice. Thus, according to Prevost, the theory of thermometric tension is incapable of explaining the experiment.

Prevost, it should be noted, treats Pictet with the greatest politeness: "He [Pictet] did not hesitate to explain the reflection of cold by that of heat in the reverse direction; but being limited (in conformity with his plan) to explanations drawn immediately from the experiment, and not having had it in view, in the important work that he has published, to treat the constitution of discrete fluids, he was not able to enter into the details that I have just given." Prevost was also very generous in assigning full credit for the general theory of discrete fluids to his old mentor, Le Sage. And
Pictet, for his part, seems to have immediately accepted Prevost's explanation of the experiment. Prevost writes: "This able physicist, with whom I have old and precious links of friendship, does not at all disapprove of the discussion that I undertake, although it tends to indicate some insufficiency in the explanation that he himself has given of this phenomenon."40

Finally, Prevost was quite enthusiastic about the possibility of extending the new theory of mobile equilibrium to other discrete fluids besides fire, and mentioned as possibilities the electric and magnetic fluids. Nearly 30 years later, Prevost published a theory of light based upon the same foundations. ${ }^{41}$ This theory of light, however, appeared too late to attract many followers. By this time (after Young's clear demonstration and explanation of interference effects) the emissionist theories of light were on the decline, a fact that Prevost himself admitted. If the general theory of the equilibrium of discrete fluids therefore failed to accomplish all that Prevost had hoped, it nevertheless helped prepare the way for thermodynamics and the kinetic theory of gases.

\section{Rumford}

Pictet's experiment produced a powerful effect on Rumford. It was, as we have seen, the immediate stimulus for the research on radiant heat that occupied him from 1800 to 1804 . Rumford's first aim in these researches was to establish the existence of frigorific rays beyond any doubt, and then to determine the laws that governed them. ${ }^{42}$ When his own investigations confirmed Pictet's discovery, Rumford accepted the existence of frigorific rays as demonstrated fact. He gently criticized Pictet for having denied the reality of the cold emanations that Pictet himself had discovered. And while Pictet everywhere spoke of the reflection of cold by metallic mirrors as merely apparent, Rumford was disposed to regard it as real. ${ }^{43}$ Rumford placed frigorific and calorific rays on entirely equal footings and even went so far as to propose that the temperature of a body is changed only by the rays that it absorbs, and not at all by the rays that it emits. Thus the cooling of a warm body is effected solely by the absorption of frigorific rays proceeding from colder bodies. ${ }^{44}$

But if frigorific rays really exist, why did they remain so long undiscovered? Rumford's explanation is that the strength of the effect depends upon the temperature interval. While we are often exposed to the influence of objects heated several thousand degrees above the temperature of the skin, it is very seldom that we have the opportunity of experiencing the radiation from objects that are much colder than ourselves, and we have no means of obtaining degrees of cold that bear any proportion to the intense heat produced by fire. Thus, frigorific radiation would never have been discovered without the use of instruments much more sensitive than our organs of sense. ${ }^{45}$

Rumford noted that several different attempts had been made to explain Pictet's experiment on the supposition that radiant heat, or radiant caloric, had a material existence. But as a life-long opponent of the emissionist theory, he naturally found all these explanations wanting. The most plausible of these explanations was, according to Rumford, that of Pierre Prevost. It is true that Rumford does not mention Prevost by name, but he lists Prevost's assumptions so clearly that there can be no doubt whose theory he had in mind: (1) caloric is emitted continually by all bodies, 
at all temperatures, but in greater abundance by hot bodies; (2) a body simultaneously emits radiant caloric and receives it in return from all the bodies surrounding it; (3) a constant temperature results from the quantities of caloric emitted and absorbed being continually equal. Against this plausible theory, Rumford objects that it is impossible to explain how the same body could receive and retain, and reject and drive away, the same substance at one and the same time. This is "an operation not only incomprehensible, but apparently impossible, and to which there is nothing to be found analogous, to render it probable... ."46

Rumford also put to use his experiments with the thermoscope, in an attempt to demonstrate the impossibility of explaining the radiation of cold in terms of a material theory of heat. He recalls the experiment, described above, in which a cylinder $40^{\circ}$ above room temperature and a cylinder $40^{\circ}$ below room temperature were simultaneously presented to opposite sides of one ball of the thermoscope. The temperature of the thermoscope was not changed by the simultaneous action of these two bodies. Rumford admits that this is easily explained by the material theory of heat. The ball of the thermoscope gives off radiant caloric in all directions and receives it in return from the bodies by which it is surrounded. The ball receives more caloric from the hot cylinder than it gives back to it. Similarly, the ball receives less caloric from the cold cylinder than it emits in that direction. As the temperature of the ball is the arithmetic mean of the temperature of the two cylinders, it is quite reasonable to suppose that the ball's unfavorable exchanges with the cold cylinder exactly compensate for its favorable exchanges with the hot cylinder. Consequently, the ball's original stock of caloric, and its temperature, remain unchanged. So far, so good. But here is an experiment that, according to Rumford, cannot be explained on these principles:

When the same two cylinders (one hot and one cold) were blackened and again presented to the same ball of the thermoscope, the temperature of the thermoscope again remained invariable. Now, when a metallic surface is blackened, its radiation at a given temperature is greatly increased. Just as the radiation of the hot cylinder was increased by blackening, so too was the radiation of the cold cylinder increased by the same means. But if both these radiations are caloric, how did it happen that the ball of the thermoscope, instead of being more heated by the additional caloric that it received in consequence of blackening the cold cylinder, was actually more cooled?

Although Rumford's argument here appears strong, it is, in fact, easily answered. The chief flaw is that Rumford has neglected to consider the radiant caloric emitted by the ball of the thermoscope and reflected back at it by the cylinders. If this reflected radiation is taken into account, there is no difficulty in explaining the thermoscope experiment in terms of a material theory of heat. ${ }^{47}$

Rumford's own explanation of the radiation and reflection of cold was thoroughly undulationist in nature. As suggested at the beginning of this article, Rumford regarded radiant heat as an undulation analogous to sound, and seems to have viewed Pictet's experiment more or less as a case of a driven oscillator: "The cold body in one focus compels the warm body (the thermometer) in the other focus to change its note." This was the explanation he ventured to offer his companions at Edinburgh in 1800. Later, in his paper of 1804, he gave a more or less complete sketch of his view of radiant heat.
To begin, imagine a bell, or any other body perfectly elastic, placed in a perfectly elastic fluid medium and surrounded by other perfectly elastic bodies. When the bell is struck and made to vibrate, its vibrations are gradually communicated, by means of the undulations or pulsations they occasion in the elastic fluid medium, to the other surrounding bodies. If these bodies should happen already to be vibrating at the same frequency with which the bell vibrates, the undulations occasioned in the elastic medium by the bell would neither increase nor diminish the frequency of the vibration of the surrounding bodies; nor would the undulations caused by the vibrations of these bodies tend to accelerate or retard the vibrations of the bell. But if the vibrations of the bell were more frequent than those of the surrounding bodies, the undulations produced by the bell in the elastic fluid would tend to accelerate the vibrations of the surrounding bodies. On the other hand, the slower vibrations of the surrounding bodies would retard the vibrations of the bell. The bell and the surrounding bodies would continue to affect one another until, by the vibrations of the latter being gradually increased and those of the former diminished, they would be reduced to the same tone.

Now, if heat is assumed to be nothing more than the vibrations of the constituant particles of a body, the cooling of a hot object by radiation will entail a series of actions and reactions similar to those just described for the case of the bell. The rapid undulations produced in the surrounding ethereal fluid will act as calorific rays on the neighboring bodies, and the slower undulations produced by the vibrations of these colder bodies will act as frigorific rays on the hot body. These reciprocal actions will continue until the hot body and the colder bodies around it have acquired the same temperature, i.e., until their vibrations have become isochronous.

It follows that cold and heat are relative terms. The rays from one particular object will be either frigorific or calorific, according as they impinge on other objects either warmer or colder than itself. Imagine three identical bodies, $A, B$, and $C$. Let $A$ be at the temperature of freezing water, $B$ at the temperature of $72^{\circ} \mathrm{F}$, and $C$ at $112^{\circ} \mathrm{F}$. The rays emitted by $B$ will be calorific with respect to the colder body $A$, but frigorific with respect to $C$. Moreover, they will be just as efficacious in heating the former as in cooling the later.

According to this hypothesis, cold can with no more propriety be considered as the absence of heat than a low or grave sound can be considered as the absence of a higher or more acute pitch; and the admission of rays which generate cold involves no absurdity and creates no confusion of ideas. ${ }^{48}$

The application of Pictet's experiment is immediate and obvious. The rapid vibrations of the particles of the thermometer produce rapid undulations in the surrounding elastic fluid. These undulations arrive, after two reflections, at the cold body, where they act to raise its temperature. Simultaneously, the slower vibrations of the cold body give rise to slower undulations in the elastic medium which proceed, again by means of two reflections, to the thermometer. The accumulation of these frigorific rays in the thermometer causes its temperature to fall. And, concludes Rumford, "...this is what actually happened in the celebrated experiment of my ingenious friend, Professor Pictet, of Geneva." 49 
Rumford thus explains the experiment solely in terms of frequencies of vibration. That is, he assumes that the "difference of temperature depends solely on the difference of the times of the vibrations of the component particles of bodies." This assumption, however, was made only for the purpose of simplifying the discussion. Rumford remarks that it is possible, even likely, that the temperature difference depends on the velocities of the particles. This modification of the theory was required to explain the obvious fact that the intensity of the radiation from a hot body falls off with distance. The pulsations produced in an elastic fluid by the vibrations of a body immersed in it are everywhere isochronous, but the mean speed of any individual particle of fluid diminishes with the distance from the center of the disturbance. Thus, remarks Rumford, in the case of sound, the frequency of the pulsations determines the note; but it is the velocity of the particles of the air, or the amplitude of the wave, that determines the strength or force of the sound. So too with light, it is likely that color depends on the frequency of the pulsations that constitute light, and that the heat produced by them is in proportion to their force. ${ }^{50}$

Thus it was clear to Rumford himself that the elegant analysis based on frequencies alone could not stand. Yet, the introduction of amplitudes or velocities leads to other contradictions that Rumford did not perceive. Assume that the undulations in the elastic fluid are calorific in effect if their amplitude, or perhaps their mean speed, is greater than that of the particles of the body on which they impinge. As a hot body is moved to greater and greater distances, the oscillations that it produces at a given fixed point in the fluid diminish in amplitude and velocity. Thus, if the body were removed to a great enough distance, its undulations would apparently change over from calorific to frigorific in effect-something quite without foundation in experience. The essential difficulty with Rumford's version of the undulationist theory was that he wished to associate the change in temperature experienced by an object solely with the radiation absorbed by it, and denied the temperature-changing effect of the emitted radiation. As a result, Rumford's system suffered from internal inconsistencies that did not trouble Prevost's. ${ }^{51}$

\section{E. Pictet's reaction to Rumford's memoir}

As mentioned above, Rumford read a memoir at the Academy of Geneva in which he recounted his experiments with radiant heat and cold and offered his new refutations of the material theory of heat. Pictet, who admired Rumford's work for its strong experimental foundation, translated the memoir into French. Moreover, he wrote a detailed analysis and summary of the memoir for the Bibliothèque brittanique. ${ }^{52}$ In this critique, Pictet stopped well short of endorsing Rumford's explanation of the reflection of cold.

Pictet admitted that the experiment could indeed be explained by Rumford's theory of frigorific rays, which were undulations in an etherial fluid. But he insisted that the experiment was explained quite as well by the theory of unequal exchanges of heat developed by his colleague Professor Prevost.

Rumford objected that it was impossible to conceive how the same body could simultaneously emit and receive heat particles, and asserted that there was in nature not a single analogous process. Pictet responded that, on the contrary, such an operation was easily conceivable. And, as an example of an analogous process, he mentioned the ordinary electrostatic machine, which simultaneously acquires and discharges an electric charge.

Rumford objected that the material theory of heat could not explain the experiment with the thermoscope, described above, in which the simultaneous blackening of the hot and cold cylinders did not disturb the equilibrium of the instrument. Pictet pointed out that Rumford had not considered the effect of blackening on the reflection process, and offered an explanation of the experiment more or less along the lines of the explanation we have given in Ref. 47. In short, while Pictet enthusiastically accepted Rumford's experimental discoveries, he was utterly unconvinced by the count's own explanation of them.

Pictet noted that the count was continuing his researches and had even discovered some new facts that appeared to support the theory of vibrations. He then concluded his analysis of the count's memoir with the following pledge:

...we shall assign ourselves the duty of following, step by step and with impartiality, the development of this great process, in measure as we obtain new communications; and, caloristes that we have been up till the present, attached by preference to the system of real emission, we shall be ready to adopt frigorisme and the hypothesis of vibrations when the rigorous consequences of decisive and incontestable experiments have convinced us.

In saying this, Pictet was merely practicing the ordinary, good professional manners of the day.

\section{F. Concluding remarks}

Pierre Prevost had claimed that only the emissionist theory of discrete fluids could explain the reflection of cold. Rumford claimed as much for the undulationist theory. Few others were so sure. Pictet, for example, admitted the equal explanatory powers of the two theories; consequent$1 y$, the discovery of the reflection of cold had little power to affect his own theoretical inclinations. And this was, ultimately, the reaction of the majority of contemporary physicists. Pictet's discovery of the reflection of cold had stimulated new research-both experimental and theoretical. But the strange phenomenon was finally taken in stride by both camps, and it failed to provide the decision that both Rumford and Prevost had hoped for.

A generous, but not unjust, appraisal of the importance of Pictet's discovery, and of Prevost's theory of exchanges, was made by Fourier, the founder of the mathematical theory of heat conduction. This lion of the new generation of physicists wrote to Prevost, then in his 67th year:

I regard the experiments of $M$. Pictet as fundamental, because they have directed the view of physicists on an order of phenomena that one had scarcely perceived. The use that he made of the air thermometer, the formal experiment on the reflection of cold, and the theory that you have given on this subject have created this new branch of physics. $^{53}$

\section{QUALITATIVE EXPLANATION OF PICTET'S EXPERIMENT}

As the radiation and reflection of cold may appear paradoxical, it may not be amiss to offer a qualitative explanation of Pictet's experiment in modern terms. 
(a)

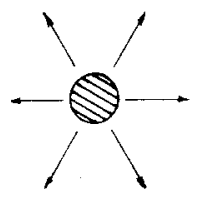

(b)

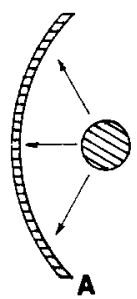

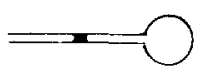

Fig. 5. For use in explaining Pictet's experiment.

Let us note that every object-even a cold object-continually emits radiation. Each object also continually receives radiation that has been emitted by the objects surrounding it. The energy emitted per unit time by a given object depends both upon the object's temperature and the properties of its surface. A highly polished metal mirror is a very poor absorber of infrared radiation; it is also, consequently, a poor radiator. Thus we may safely ignore any emission or absorption of radiant heat by the mirrors themselves. The sole function of the mirrors then consists in the reflection of the radiation that is incident upon them.

Consider first the version of the experiment involving a flask of boiling water. This flask emits radiation in all directions, as shown schematically in Fig. 5(a). A negligible part of this radiation is received directly by the air thermometer, which has but a small cross-sectional area and which is placed at a considerable distance from the flask. In Fig. 5(b), we imagine the mirrors to be placed so that the focus of mirror $A$ lies in the flask, and the focus of $B$ in the bulb of the thermometer. Now we direct our attention toward that part of the radiation from the flask which happens to strike mirror $A$. This radiation will, after two reflections, impinge on the bulb of the thermometer. This is radiation that the thermometer did not receive prior to the introduction of the mirrors. Of course, the thermometer also receives radiation from other objects in the room. The introduction of mirror $B$ effectively eliminates the right third or half of the room as a source of radiation for the thermometer. The effect of the mirrors is therefore to replace a part of the ambient radiation that formerly impinged on the thermometer by the more intense radiation from the flask. The thermometer therefore grows a little warmer.

The version of the experiment involving a flask of snow may be explained in a similar way. Before the mirrors are introduced, the air thermometer receives radiation from all the objects in the room surrounding it. After the introduction of the mirrors, the radiation from the right third or half of the room is cut off from the thermometer by mirror $B$. This relatively high-temperature radiation is replaced by the radiation from the flask of snow. The thermometer now receives less energy per unit time than previously. The thermometer, initially at room temperature, now radiates away more energy than it absorbs, and so suffers a decrease in temperature.

\section{PICTET'S EXPERIMENT AS A LECTURE DEMONSTRATION}

Figure 1 illustrates the essential features of the experiment. Many university physics departments are no doubt equipped with all that is required. The mirrors need not be of very high optical quality, but if they are of glass they must be front-surface reflectors, as glass is a strong absorber of both hot and cold emanations-a point made quite clearly by Pictet himself. ${ }^{54}$

In an arrangement designed by $J$. Davis and used at the University of Washington, the reflectors are $25 \mathrm{~cm}$ in diameter, with focal lengths of about $2 \mathrm{~cm}$. A brass sphere, which may be heated over a Bunsen burner or plunged into liquid nitrogen, serves as the hot or cold object and is mounted on a stand at the focus of one reflector. At the focus of the other is a thermopile, which is connected to a projection galvanometer so that changes in temperature can be observed by a large audience. Full-scale deflection of the galvanometer is achieved for the radiation of both hot and cold.

Those without large reflectors and adequate temperature-sensing equipment should not despair, for perfectly acceptable homemade apparatus can be assembled in a few hours and for a few dollars. The homemade equipment, by dispensing with such historical anomalies as liquid nitrogen and projection galvanometers, actually results in a demonstration that is more pleasing and convincing.

For the cold object, a glass beaker of ice water works well enough. Glass, being a good absorber of infrared radiation, is also a good emitter. A metal can should not be used unless the metal is blackened. Colder temperatures can be obtained, if necessary, by using ice and salt, or by using dry ice.

A sensitive air thermometer may be quickly constructed from a flask, a one-hole stopper, and a bent glass tube, as shown in Fig. 6. A bead of colored water or alcohol is inserted in the glass tube before the stopper is seated in the neck of the flask. A small card, marked with uniform but otherwise arbitrary divisions, may be taped to the tube to make the motion of the water more apparent. The glass of the flask is probably already a sufficiently good absorber of infrared radiation; but a curl of black paper inserted in the flask may increase absorption somewhat. The thermometer should respond instantly to the touch, or even the close proximity, of the hand. If it does not, one of the two seals (of the stopper in the flask, or of the tube in the stopper) is probably not air-tight.

The thermometer just described is quite sensitive and can be easily observed by the whole audience in even a rather large room. But as the thermometer is rather bulky,

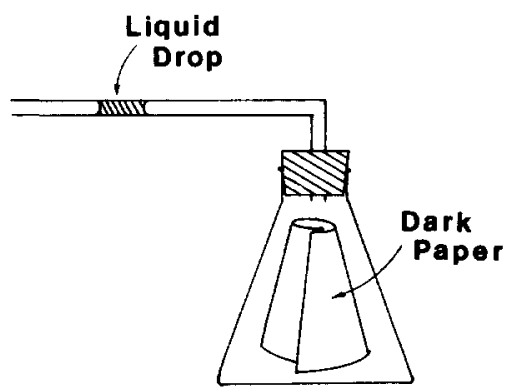

Fig. 6. A simple air thermometer. 

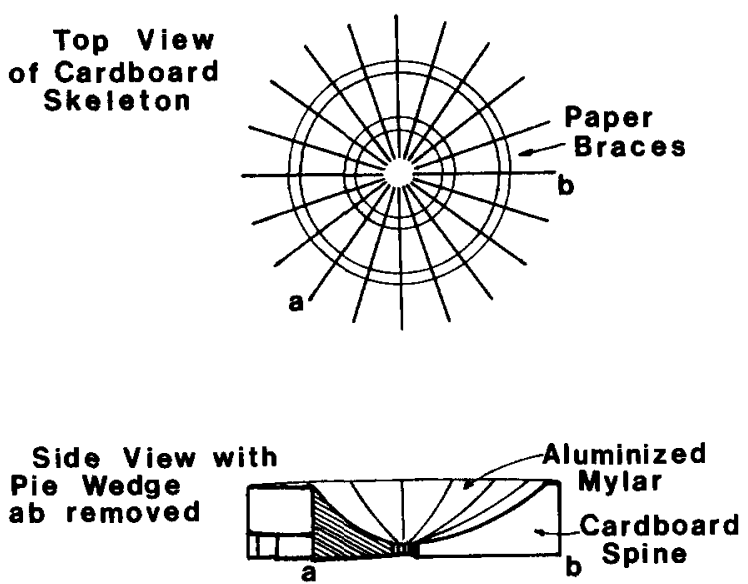

Fig. 7. Design of an inexpensive mirror for reflecting cold emanations.

it requires the use of mirrors of fairly long focal length. Since the mirrors need be of only minimal quality, they can be made from a sheet of aluminized mylar. Cardboard spines are cut with the appropriate circular or parabolic shape, as shown in Fig. 7. (Our reflectors are approximately $55 \mathrm{~cm}$ in diameter and have a focal length of $15 \mathrm{~cm}$.) These spines are then fastened together with strips of stiff paper to form the skeleton of the reflector, as shown. Paper strips are then pasted to the skeleton, completely covering it. This provides added sturdiness and a base on which to apply the aluminized mylar. The mylar is fastened in thin, wedgeshaped pieces with double-stick tape. The finished mirror will, of course, have many little warps and bubbles and will be completely unsuitable for optical experiments, but it will be more than adequate for experiments with radiant heat. The large diameter of the reflector more than compensates for the imperfections of its surface.

\section{ACKNOWLEDGMENTS}

Mr. Evans wishes to acknowledge the support of a Fulbright grant, as well as the warm welcome accorded him by the Centre Koyré, École des Hautes Études en Sciences Sociales, during his stay in France.

\footnotetext{
${ }^{1}$ Thomas Charles Hope (1766-1844), professor of chemistry at the University of Edinburgh for nearly 50 years. John Playfair (1748-1819), best known today for his Illustrations of the Huttonian Theory of the Earth (Edinburgh, 1802). Appointed professor of mathematics in 1785, he exchanged this chair for the chair of natural philosophy in 1805. Dugald Stewart (1753-1828) succeeded his father Matthew Stewart as professor of mathematics. He is said to have been a successful teacher but to have groaned at the prospect of teaching Euclid for the thirteenth time. In 1785 he transferred to the chair of moral philosophy.

${ }^{2}$ Rumford's account of this experiment is given in his "Historical Review of the Various Experiments of the Author on the Subject of Heat," first published in French in his Mémoires sur la chaleur (Paris, 1804). The English version appears in The Collected Works of Count Rumford, edited by S. C. Brown (Harvard University, Cambridge, 1968-1970), Vol. I, pp. 443-496. The repetition of Pictet's experiment is found on pp. 477478 of Brown's edition. Rumford had long espoused vibrationist views [see M. Watanabe, "Count Rumford's First Exposition of the Dynamic Theory of Heat," Isis 50, pp. 141-144 (1959)]; but it was in Edinburgh in 1800 that he first publicly asserted an analogy between heat and sound. ${ }^{3}$ For an overview, see E. S. Cornell, "Early Studies in Radiant Heat," Ann. Sci. 1, 217-225 (1936). The account by A. Wolf, A History of Science, Technology, and Philosophy in the Eighteenth Century (George
}

Allen \& Unwin, London, 1952), 2nd ed., pp. 206-212, is based largely on Cornell's article.

${ }^{4}$ This experiment was performed, for example, by Zahn, Hoffman, Scheele, and Lambert. See Wolf, History, pp. 206-209. The experiment is mentioned by Saussure as one that is "well known": H.-B. de Saussure, Voyages dans les Alpes (Neuchatel, 1779-1796), Vol. 2, p. 353.

${ }_{5}^{5}$ Johann Heinrich Lambert (1726-1777), best known to mathematicians for his proof of the irrationality of $\pi$ and $e$. In physics, his name is attached to (1) the exponential decrease of the intensity of light passing through a homogeneous absorbing medium, as well as to (2) Lambert's cosine law, which states that the intensity of light emitted by a diffusely radiating plane surface is proportional to the cosine of the angle between the line of sight and the normal to the surface. Lambert's investigations into the measurement, radiation, and reflection of heat are reported in his Pyrometrie oder vom Maasse des Feurers und der Wärme (Berlin, 1779).

${ }^{6}$ Carl Wilhelm Scheele (1742-1786), the extraordinarily productive and talented chemist from Swedish Pomerania. His research on gases culminated in his discovery of oxygen in advance of Priestly. This work, as well as his investigation into radiant heat, was reported in his Chemische Abhandlung von Luft und dem Feuer (Upsala and Leipzig, 1777; 2nd ed., Leipzig, 1782). A French translation by Dietrich was published in 1781 with the approbation of the Académie des Sciences, under the title, Traité chemique del'air et du feu (Paris, 1781), through which Scheele's work became widely known in France and in French Switzerland. The German edition of 1782 has been reprinted as Vol. 58 of Ostwald's Klassiker der exakten Wissenschaften (W. Englemann, Leipzig, 1894). There is an English translation in L. Dobbin, The Collected Papers of Carl Wilhelm Scheele (G. Bell \& Sons, London, 1931).

${ }^{7}$ Lambert, Pyrometrie, Sec. 378. The use of a pane of glass to halt the progress of radiant heat was a standard experiment. It had already been demonstrated a hundred years before by Mariotte: Histoire de l'Académie Royale des Sciences depuis son établissement en 1666 jusqu'à 1686, Vol.I (Paris, 1733), p. 344. Mariotte also showed that the heat from the sun differed from that of a fire, in that it was not stopped by glass. The notion of obscure heat also seems to have been in the air at the time that Lambert wrote. G. Buffon distinguished between luminous and obscure heat in his Histoire naturelle, générale et particulière...Supplément, Vol. I (Paris, 1774), p. 32. Buffon produced a "rather strong" heat without any light at the focus of a mirror by interposing a plate of iron between the mirror and a fire (p. 42, note o.)

${ }^{8}$ Scheele, Chemische Abhandlung, Secs. 56-57.

${ }^{9}$ See Ref. 8, Secs. 58, 69.

${ }^{10}$ These biological sketches of Saussure and Pictet are drawn largely from the articles in the Dictionary of Scientific Biography, edited by C. C. Gillispie (Scribner's, New York, 1976) and in the Michaud Biographie universelle (Paris, 1843-?). The latter is also an excellent source of information on the many minor 18 th and early 19 th century scientists who cannot be found in any other standard biographical reference work. For Saussure there is also a biography: D. W. Freshfield, The Life of Horace Benedict de Saussure (E. Arnold, London, 1920).

${ }^{11}$ M.-A. Pictet, Essai sur le feu (Geneva, 1790). Translated into English by W. B. [elcombe] and published as An Essay on Fire (London, 1791). Pictet intended to write a series of Essais de physique. The treatise on fire, which was the only one completed, is sometimes cited by this title as well.

${ }^{12}$ The thermometer was of mercury. Neither Saussure nor Pictet specifies the kind of degree used. Thus one should assume the degree of the 80degree scale (Réaumur) which Pictet used as a matter of course. Pictet did, however, possess at least one thermometer adapted to Farenheit's scale, made by Ramsden in London, which he used on occasion (Essai sur le feu, Sec. 53).

${ }^{13}$ Louis Bertrand (1731-1812), Swiss geologist and mathematician, and a student of Euler's. In 1761 Bertrand was appointed to the chair of mathematics at the Academy of Geneva. He wrote memoirs on probability theory and the binomioal formula but is best known for the treatment of the theory of parallels that formed a part of his Developpements nouveaux de la partie élementaire des mathématiques (Geneva, 1778). At the time of the revolution in Geneva (1793), Bertrand resigned his chair and retired to a country village, where he occupied himself with geology and produced his rather fantastic Renouvellements périodiques des continents terrestres (Hamburg, 1799; Geneva, 1803). He returned to Geneva 
only in 1799 and devoted his last years to perfecting his Elements de géométrie (Geneva, 1812), a work that became classic at Geneva.

${ }^{14}$ Pictet, Essai sur le feu, Sec. 69. We have quoted from Belcombe's English translation, pp. 116-118. The use of relatively weak sources of heat and cold, such as matrasses of boiling water or snow, forced Pictet to abandon the mercury thermometers he had used in the earlier experiments with hot bullets and lighted tapers. He settled on air thermometers as the most sensitive type available. He originally had some prejudice against them, on account of their barometric effect, but this shortcoming could be eliminated by calibrating them anew before each use. Pictet's discussion of the use of these instruments illustrates the care he ordinarily brought to his work. He blew a bulb about a third of an inch in diameter, and as thin as possible, at the end of a glass tube 8 or 10 in. long and of the caliber "usually employed for a mercury thermometer of the larger size." $A$ short bead of colored alcohol was drawn into the tube by first warming the bulb between thumb and finger and then plunging the open end of the tube into a container of this fluid. The tube was graduated according to arbitrary divisions and then calibrated by suspending it near sensitive mercury thermometers in warm and in cold warms. During the calibration process, it was necessary to observe the thermometers through a glass, for Pictet found that he could not approach them without his body heat causing them to vary. He found most convenient an air thermometer on which an interval of $2 \mathrm{in.} \mathrm{corre-}$ sponded to one degree of Réaumur's scale (Essai sur le feu, Sec. 56).

${ }^{15}$ Pictet, Essai sur le feu, Sec. 69; Belcombe, p. 117.

${ }^{16}$ The authoritative treatment of the Accademia del Cimento is that of $\mathrm{W}$. E. K. Middleton, The Experimenters: A Study of the Accademia Del Cimento (The Johns Hopkins Press, Baltimore and London, 1971). Middleton includes a complete English translation of the Saggi di naturali esperienze, and it is from this translation that we have quoted (p. 205).

${ }^{17}$ Rumford, "Inquiry Concerning the Nature of Heat and the Mode of its Communication," Philos. Trans. R. Soc. London 94, pp. 77-182 (1804). A French translation appeared in Rumford's Mémoires sur la chaleur, published in the same year. The original English version is reprinted in Rumford, Collected Works (Vol. I, p. 373).

${ }^{18}$ The academicians themselves were far from the first to try the experiment of the reflection of cold. They were preceded by Sir Christopher Heydon, around 1650; by Giovanni Antonio Magini, who died in 1617 (see Middleton, The Experimenters, pp. 205-206n); and by Baptista Porta, around 1589 (see Cornell, "Early Studies," p. 217). In some of these cases the validity of the experiment is doubtful. Typically, the reflected cold was detected by placing a hand, or even an eye, at the focus of the mirror. The question of priority is therefore rather difficult-and probably not very important.

${ }^{19}$ S. C. Brown, Benjamin Thompson, Count Rumford (MIT, Cambridge, 1979), p. 232.

${ }^{20}$ Rumford, "Historical Review," Collected Works, Vol. I, pp. 477-480.

${ }^{21}$ For Pictet's relations with Rumford during Pictet's tour of Britain, see Pictet's letters to the Bibliothèque britannique (Series Sciences et arts): "Neuvième lettre," 19, pp. 372-400 (1802); "Dixième lettre" and "Onzième lettre," 20, pp. 192-213, 406-428 (1802); "Douzième lettre,"21, pp. 190-200, 286-309 (1802).

${ }^{22}$ Albertine-Adrienne Necker de Saussure (1766-1841), daughter of H.-B. de Saussure and wife of Jaques Necker, nephew of the famous director general of finances under Louis XVI. Through this marriage, she became related to Madame de Staël, of whom she was an admiring friend. Albertine de Saussure wrote a eulogistic biographical notice of Madame de Staell after the latter's death. She also published a work in three volumes, Education progressive, ou Etude du cours de la vie (Paris, 18281838).

${ }^{23}$ Extracts from Rumford's diary quoted by Brown, Count Rumford, p. 247.

${ }^{24}$ The effect of blackening in hastening the absorption and emission of radiant heat had already been demonstrated by Scheele (Chemische $A b$ handlung, Sec. 56) and Pictet (Essai sur le feu, Sec. 58).

${ }^{25}$ Rumford, "Inquiry," Collected Works, Vol. I, p. 372.

${ }^{26}$ As is well known, John Leslie conducted a remarkably similar investigation into radiant heat, independently of Rumford and at almost exactly the same time. Leslie invented a "differential thermometer" which does not differ at all from Rumford's thermoscope. With this instrument, Leslie demonstrated the radiation and reflection of cold, proved that the effect on the differential thermometer was proportional to the difference between the temperature of the source and the room, investigated the effects of surface coatings of various kinds, etc. See J. Leslie, An Experimental Inquiry into the Nature and Propagation of Heat (London, 1804), pp. 2-21. The detailed account of Rumford's movements between 1800 and 1804 is largely due to Rumford himself ("Historical Review," Collected Works, Vol. I, pp. 477-481, 488-496). Rumford had been rudely surprised by the appearance of Leslie's book in England while he himself was in France, and took great pains to demonstrate the independence, if not the priority, of his own work. Accordingly, he mentioned by name all those with whom he had had professional contact in London, Geneva, and Paris. Additional details of Rumford's movements have been supplied from Pictet's letters to the Bibliothèque brittanique (see Ref. 21) and from Brown, Count Rumford, pp. 233-264.

${ }^{27} \mathrm{P}$. Prevost, Deux traités de physique mécanique (Geneva, 1818), p. xxxix. Prevost admits that the "second class has lately grown."

${ }^{28}$ For a discussion of the undulatory theory of heat in the first half of the nineteenth century, a period of somewhat later than that which concerns us here, see S. G. Brush, "The Wave Theory of Heat: A Forgotten Stage in the Transition from the Caloric Theory to Thermodynamics," Br. J. Hist. Sci. 5, 145-167 (1970).

${ }^{29}$ Scheele, Chemische Abhandlung, Sec. 71. One of the theories mentioned, that light is a discrete fluid whose motion in a straight line is communicated to it by the impacts of the particles of a finer, all-pervading fluid, is that of G-L. Le Sage of Geneva. (See Ref. 38.) The chemical theory of the acidum pingue was introduced by Johann Friedrich Meyer (1705-1765) in 1764.

${ }^{30}$ Jean-André De Luc (1727-1817), Swiss geologist and physicist. He passed the first half of his life in his native country and divided the remainder largely between Germany and England, where he died. The physicists of Geneva regarded him highly but often disagreed with him. In 1765 De Luc made the first ascent of Mt. Buet, and subsequently he climbed twice in the mountains of Faucigny to perform experiments on the boiling of water. His most important work in physics was his investigation of the theory and construction of barometers and thermometers, including the application of a portable barometer of his own invention to the measurement of the heights of mountains: Recherches sur les modifications de l'atmosphère, ou Théorie des baromètres et des thermomètres (Geneva, 1772; 2nd ed., Paris, 1784). He invented a hygrometer which used first ivory and then whale bone, but this was soon displaced by the hair hygrometer of Saussure. De Luc published extensively on meteorology and geology as well. A man of great religious sensibility, De Luc published essays on Christian thought and religious education and strove to reconcile the geological record with the Biblical history of the Earth. His theory of the constitution of fire, as described here, is drawn from his Idees sur la météorologie (Paris, 1787), Vol. I, pp. 103-231.

${ }^{31}$ The most extensive study of the material theories of heat is $\mathrm{R}$. Fox, The Caloric Theory of Gases, from Lavoisier to Regnault (Clarendon, Oxford, 1971). In spite of its title, the book is not confined exclusively to the theory of gases. It does, however, center on a period somewhat later than that which concerns us here.

${ }^{32}$ This is Saussure's interpretation, apparently based on De Luc's Lettres physiques et morales sur l'histoire de la terre et de l'homme, Vol. 5 (La Haye and Paris, 1799), pp. 552-558. On close reading, it is not altogether clear whether De Luc indeed regarded fire as a continuous fluid. In later works, he unmistakably treated it as a discrete fluid (see Idées sur la météorologie, Vol. I, pp. 10-11). In any case, our summary of De Luc's theory of atmospheric temperatures considerably simplifies his system.

${ }^{33}$ P. Bouguer, La figure de la terre (Paris, 1749), pp. 1-1ii.

${ }^{34}$ Saussure, Voyages dans les Alpes, Vol. 2, Secs. 923-932 (pp. 347-365).

${ }^{35}$ Pictet, Essai sur le feu, Secs. 70-71.

${ }^{36}$ For more biographical and bibliographical details on Prevost, see the article in Michaud, Biographie universelle.

${ }^{37}$ Apparently Louis de Végobre (1752-1840), a lawyer by training, like Pictet and Prevost. Végobre worked hard for the development of artistic societies and institutions at Geneva, but his interest in science was only passing.

${ }^{38}$ George-Louis Le Sage (1724-1803), an extraordinarily curious figure. Too timid to compete for a university chair, he made ends meet by giving lessons in mathematics and by living frugally. He devoted his whole life to the search for a mechanical explanation of gravity, in terms of a discrete fluid of ultramondane particles. He published almost nothing, being too distracted and disorganized to put his writings into final form. 
Le Sage nevertheless carried on an active correspondence with many of the leading scientists of the day, through which his theory became rather widely known. De Luc, for one, accepted it. Saussure and Pictet, while withholding judgment, treated Le Sage's system in their physics lectures at the Academy of Geneva. After Le Sage's death, his pupil and disciple Prevost produced a coherent account of the theory of gravity out of Le Sage's voluminous notes and joined to it a related treatise of his own in his Deux traités de physique mécanique. On Le Sage's life, the chief source is Prevost, Notice de la vie et des écrits de George-Louis Le Sage de Genève (Geneva, 1805).

${ }^{39}$ P. Prevost, "Mémoire sur l'équilibre du feu," Observations sur la physique, sur l'histoire naturelle, et sur les arts 38, 314-323 (1791). This periodical, whose publication history is rather complicated, is sometimes cited by the title, Journal de physique.

${ }^{40}$ See Ref. 39, 315, 319. Prevost continued to push his theory in subsequent publications. See, for example, his Recherches physico-mécaniques sur la chaleur (Geneva, 1792), pp. 10-15. A decade later, he attempted to disseminate the theory in Britain by appending a full description of it to his criticism of some of Herschel's experiments on the absorption of radiant heat: P. Prevost, "Quelques remarques sur la chaleur, et sur l'action des corps qui l'interceptent," Philos. Trans. R. Soc. London, 403-447 (1802). (This paper was communicated to the Royal Society for Prevost by Thomas Young.) By 1818, Prevost was able to say that his theory had been accepted by a number of "celebrated physicists." Besides Pictet, he mentioned Biot, William Charles Wells, and René-Just Haüy (Deux traités de physique mécanique, p. 236). Haüy, the distinguished crystallographer, embraced the theory of mobile equilibrium without, however, mentioning Prevost by name in the textbook he wrote for use in the French Lycées: Traité elementaire de physique (Paris, 1803), Vol. I, p. 118.

${ }^{41}$ Prevost, Deux traités de physique mécanique, Second Treatise, Book II.

${ }^{42}$ Rumford, "Historical Review," Collected Works, Vol. I, p. 479; and

“Inquiry," Collected Works, Vol. I, pp. 361-362.

${ }^{43}$ Rumford, "Inquiry," Collected Works, Vol. I, pp. 373-374.

${ }^{44}$ See Ref. 43, pp. 361, 414.

${ }^{45}$ See Ref. 43 , p. 372.

${ }^{46}$ See Ref. 43, pp. 421-422.

${ }^{47}$ Such an explanation might run as follows. Consider first the hot cylinder. This cylinder simultaneously emits and absorbs radiant caloric, but as it is in the act of cooling, it clearly emits more than it absorbs. Blackening the cylinder increases the efficiency of both processes, but increases emission more, as this process was already the dominant one for the hot cylinder. Now, the ball of the thermoscope receives two kinds of radiant caloric from the direction of the hot cylinder: caloric emitted directly by that cylinder, and caloric emitted originally by the ball of the thermoscope but reflected back at it by the cylinder. Again, blackening the cylinder increases the quantity of the first kind of caloric and diminishes that of the second. But the increase in direct emission by the hot cylinder more than compensates for the decrease in reflection. Consider now the cold cylinder. For this cylinder, which is in the act of warming, absorption is more important than emission. Blackening the cylinder increases the efficiency of both processes, but increases absorption more, since absorption is the predominant process for this cylinder. Thus the quantity of caloric radiated directly by the cold cylinder is increased by blackening, but the quantity of caloric emitted by the ball of the thermoscope and reflected back at it by the cold cylinder is even more strongly decreased. Blackening both cylinders therefore increases the radiant caloric emitted by both, exactly as Rumford noted, but it also decreases the amount reflected by both back towards the thermoscope. The decrease in reflection then compensates for the increase in direct emission.

${ }^{48}$ Rumford, "Inquiry," Collected Works, Vol, I, p. 408.

${ }^{49}$ See Ref. 48, p. 421

${ }^{50}$ See Ref. 48 , pp. $427-428$.

${ }^{51}$ As mentioned above (see Ref. 26), Leslie and Rumford published their studies of radiant heat almost simultaneously. For Rumford, the radiation of cold was one of the crucial phenomena to be explained. For Leslie, it had nowhere near the same importance. Leslie does, however, provide a brief explanation which is a curious blend of emissionist and undulationist ideas. Leslie insists quite strongly that heat is a material substance. In the case of radiation, the substance of heat causes zones of rarefaction in the air. These rarefied zones propagate like waves and carry the heat substance along with them at the speed of sound. In the case of radiant cold, the direction of motion of the substance of heat is opposite to that of the (compressional) aerial pulses. See Leslie, Experimental Inquiry, pp. 241-243. For a comparison of Rumford's and Leslie's ideas on many different aspects of heat, see R. G. Olson, "Count Rumford, Sir John Leslie, and the Study of the Nature and Propagation of Heat at the Beginning of the Nineteenth Century," Ann. Sci. 26, 273304 (1970).

${ }^{52}$ Bibliothèque britannique 25, pp. 185-221, 273-311 (1804).

${ }^{53}$ J. B. J. Fourier, letter to P. Prevost, 22 October 1817. Quoted by Prevost in Exposition élémentaire des principes qui servent de base à la théorie de la chaleur rayonnante, faisant suite à l'ouvrage intitulé Du Calorique rayonnant (Geneva, 1832), pp. 86-93.

${ }^{54}$ Pictet, Essai sur le feu, Sec. 67.

\title{
The hydrogen atom as a Morse oscillator
}

\author{
Soo-Y. Lee \\ Faculty of Science, National University of Singapore, Kent Ridge, Singapore 0511 Singapore
}

(Received 24 February 1984; accepted for publication 24 July 1984)

In its radial motion, the electron in the hydrogen atom can be pictured as oscillating about the Bohr orbits under Morse potentials. For each principal quantum number $n$, there corresponds a Morse oscillator with $n$ bound states-one for each allowed value of the angular momentum quantum number $l$. The equilibrium positions of the Morse oscillators are exactly the Bohr orbits.

\section{INTRODUCTION}

The hydrogen atom inspired the beginnings of quantum mechanics. It is simple in structure-consisting of just a proton and an electron; and, to this day, it continues to be used as a test of the predictions of quantum mechanics. It occupies an important position in both the physics and chemistry curricula - in the early part of the course it is introduced as the Bohr atom, ${ }^{1-3}$ and later as the Coulomb problem in nonrelativistic quantum mechanics. ${ }^{4-6}$ How- 